\title{
Numerical Study on Flow and Heat Transfer Mechanisms in the Heat Exchanger Channel with V-Orifice at Various Blockage Ratios, Gap Spacing Ratios, and Flow Directions
}

\author{
Amnart Boonloi ${ }_{(D)}^{1}$ and Withada Jedsadaratanachai ${ }^{2}{ }^{2}$ \\ ${ }^{1}$ Department of Mechanical Engineering Technology, College of Industrial Technology, \\ King Mongkut's University of Technology North Bangkok, Bangkok 10800, Thailand \\ ${ }^{2}$ Department of Mechanical Engineering, Faculty of Engineering, King Mongkut's Institute of Technology Ladkrabang, \\ Bangkok 10520, Thailand \\ Correspondence should be addressed to Withada Jedsadaratanachai; kjwithad@kmitl.ac.th
}

Received 12 November 2018; Accepted 3 April 2019; Published 28 April 2019

Academic Editor: Jing-song Hong

Copyright (C) 2019 Amnart Boonloi and Withada Jedsadaratanachai. This is an open access article distributed under the Creative Commons Attribution License, which permits unrestricted use, distribution, and reproduction in any medium, provided the original work is properly cited.

\begin{abstract}
Numerical assessments in the square channel heat exchanger installed with various parameters of $\mathrm{V}$-orifices are presented. The $\mathrm{V}$-orifice is installed in the heat exchanger channel with gap spacing between the upper-lower edges of the orifice and the channel wall. The purposes of the design are to reduce the pressure loss, increase the vortex strength, and increase the turbulent mixing of the flow. The influence of the blockage ratio and V-orifice arrangement is investigated. The blockage ratio, $b / H$, of the $\mathrm{V}$-orifice is varied in the range $0.05-0.30$. The V-tip of the V-orifice pointing downstream (V-downstream) is compared with the V-tip pointing upstream (V-upstream) by both flow and heat transfer. The numerical results are reported in terms of flow visualization and heat transfer pattern in the test section. The thermal performance assessments in terms of Nusselt number, friction factor, and thermal enhancement factor are also concluded. The numerical results reveal that the maximum heat transfer enhancement is found to be around 26.13 times higher than the smooth channel, while the optimum TEF is around 3.2. The suggested gap spacing for the present configuration of the V-orifice channel is around $5-10 \%$.
\end{abstract}

\section{Introduction}

The development method for the various types of the heat exchanger has been widely reported by many researchers. The development method for the heat exchanger can be separated into two ways: (1) passive method and (2) active method. The active method is to add the external power such as vibration, to increase the heat transfer rate and efficiency. Therefore, the use of the active method must consider on both the additional power cost and the benefit of the system. The passive method is to generate the vortex flow or swirling flow and to disturb the thermal boundary layer by installed with vortex generator or turbulators such as baffle, rib, winglet, wing, etc., in the heating system. The improvement of the thermal performance for the heat exchanger with passive method is widely selected because this method does not consider the additional power cost of the system.
The investigations of the thermal performance augmentation in the heat exchanger are divided into two methods: (1) numerical method and (2) experimental method. The experimental method gives high reliability result, but the operation cost is more expensive than the numerical study. The numerical investigation can help to describe the mechanisms in the system that is an important knowledge to design and improve the thermal performance of the heating system. However, the researchers must sure that the computational model has more reliability to predict the flow and heat transfer in the channel when studied with numerical method.

The selection of the vortex generator type depends on the application of the heat exchanger. The baffle and rib always select to enhance heat transfer rate and performance in the channel or tube heat exchanger [1-5]. The baffle and rib give high heat transfer rate and thermal efficiency when compared with the other types of the generators, especially, 
V-shaped rib/baffle [6-15]. However, it is found that the installation of the V-rib is quite difficult. The V-rib in the heat section had been modified to help to support the installation and maintenance, while the benefit of the V-rib nearly remains the general type. The structure of the V-rib is developed like as orifice plate when considered at the projected view [16]. The researchers found that the modified V-rib can enhance the heat transfer rate nearly as the $\mathrm{V}$-rib, but the pressure loss of the system is extremely found.

In the present work, the orifice is modified like $\mathrm{V}$-baffle (called "V-orifice") and inserted in the square channel heat exchanger. The purpose for the insertion of the $\mathrm{V}$-orifice is to generate the vortex flow through the test section. The vortex flow will disturb the thermal boundary layer on the heat transfer surface causing heat transfer rate and thermal performance enhancements. The installation of the $\mathrm{V}$-orifice in the channel is designed with gap spacing between edges of the orifice and the channel walls. The optimum gap spacing may increase the turbulent mixing, help to distribute the fluid temperature, and also reduce the pressure loss in the tested channel. The numerical investigation is selected to solve the current problem. The numerical study helps to describe the mechanisms in the heating channel that is an important knowledge to develop the thermal performance of the heat exchanger. The flow visualization and heat transfer behavior in the test channel are shown. The thermal analysis for the present problem is also concluded.

\section{Physical Domain of the Square Channel with V-Orifice}

The V-orifices are inserted in the square channel heat exchanger as shown in Figure 1. The square channel height, $H$, is set around $0.05 \mathrm{~m}$. The orifice height (projected view) is represented with " $b$." The ratio between orifice height and the channel height, $b / H$, is called blockage ratio. The blockage ratio is varied in the range around $0.05-0.30$. The gap spacing between the edges of the orifice and the channel walls is represented with " $g$." The ratio between gap spacing and channel height, $g / H$, is known as the gap spacing ratio. The gap spacing ratio is varied in the range around $0-0.35$. The laminar flow regime (inlet condition) with the Reynolds number around 100-2000 is considered for the present investigation. " $P$ " is the distance between the $\mathrm{V}$-orifice. The $\mathrm{P} / \mathrm{H}$ or pitch spacing ratio is fixed at 1 . The flow attack angle for the V-orifice is set around $30^{\circ}$ for all examples. The V-tip arrangement of the $\mathrm{V}$-orifice is divided into two directions: $\mathrm{V}$-tip pointing downstream (V-downstream) and V-tip pointing upstream ( $\mathrm{V}$-upstream). The investigated cases and code are concluded as Table 1.

\section{Assumption}

The numerical model of the heat exchanger square channel inserted with V-orifice is developed with the following assumptions:

(1) The test fluid is air with $300 \mathrm{~K}(\mathrm{Pr}=0.707)$
(2) The flow and heat transfer is steady in three dimensions

(3) The flow is incompressible

(4) Laminar flow regime is measured

(5) The convective heat transfer is considered for the present work, while natural convection and radiation heat transfer are ignored

(6) The body force and viscous dissipation are disregarded

(7) The properties of the air assume to be constant at the average bulk mean temperature

(8) No slip wall condition is applied for all surfaces

(9) The uniform temperature of the channel walls is maintained around $310 \mathrm{~K}$

(10) The V-orifice plate assumes to be an insulator

\section{Boundary Condition and Initial Condition}

The boundary condition and initial condition for the numerical model of the square channel inserted with the $\mathrm{V}$-orifice are given in Table 2.

\section{Mathematical Foundation and Numerical Method}

The numerical problem is answered by the finite volume method (SIMPLE algorithm). The tested channel is governed by the continuity, the Navier-Stokes equations, and the energy equation as equations (1)-(3), respectively.

Continuity equation:

$$
\frac{\partial}{\partial x_{i}}\left(\rho u_{i}\right)=0 .
$$

Momentum equation:

$$
\frac{\partial\left(\rho u_{i} u_{j}\right)}{\partial x_{j}}=-\frac{\partial p}{\partial x_{i}}+\frac{\partial}{\partial x_{j}}\left[\mu\left(\frac{\partial u_{i}}{\partial x_{j}}+\frac{\partial u_{j}}{\partial x_{i}}\right)\right] .
$$

Energy equation:

$$
\frac{\partial}{\partial x_{i}}\left(\rho u_{i} T\right)=\frac{\partial}{\partial x_{j}}\left(\Gamma \frac{\partial T}{\partial x_{j}}\right),
$$

where $\Gamma$ is the thermal diffusivity and is written as

$$
\Gamma=\frac{\mu}{\operatorname{Pr}} \text {. }
$$

The continuity and momentum equations are discretized by the power law scheme, while the energy equation is discretized by QUICK scheme. The solutions are determined to be converged when the normalized residual values are less than $10^{-5}$ for all variables, but less than $10^{-9}$ only for the energy equation.

The velocity of the flow is presented in terms of the Reynolds number as equation (5). The pressure loss of the tested section is shown with the friction factor (equation (6)), while the heat transfer rate is concluded with the local Nusselt number and average Nusselt number (equations (7) 


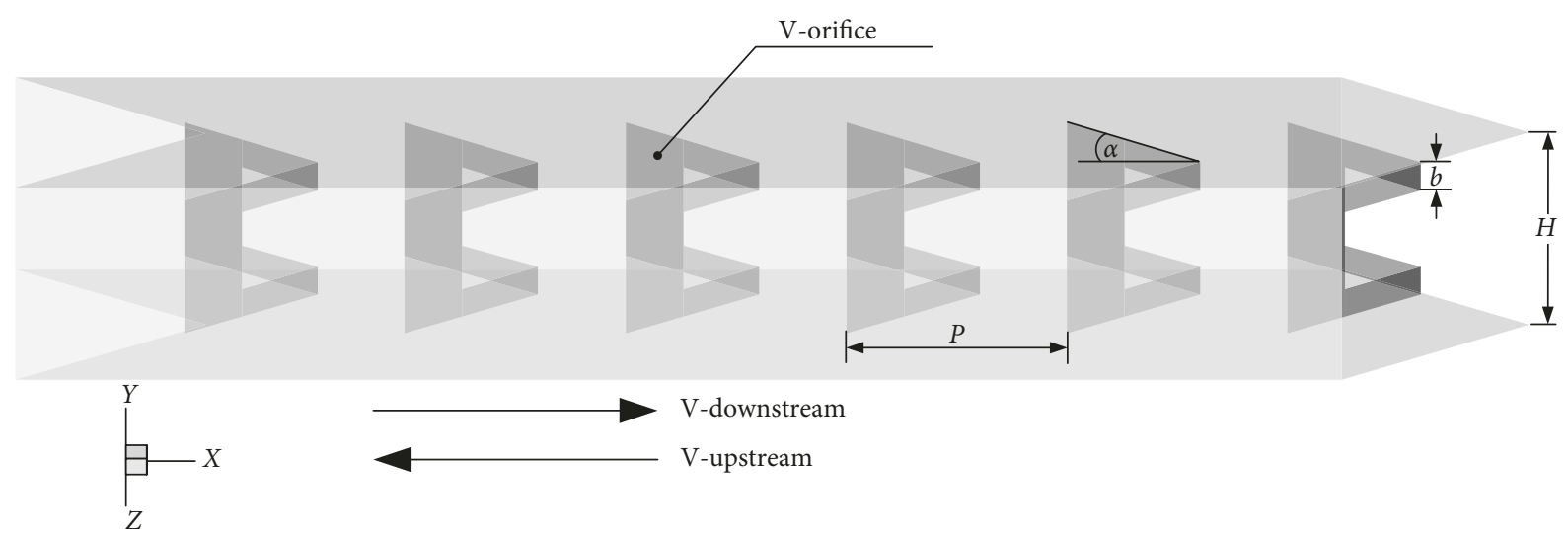

(a)

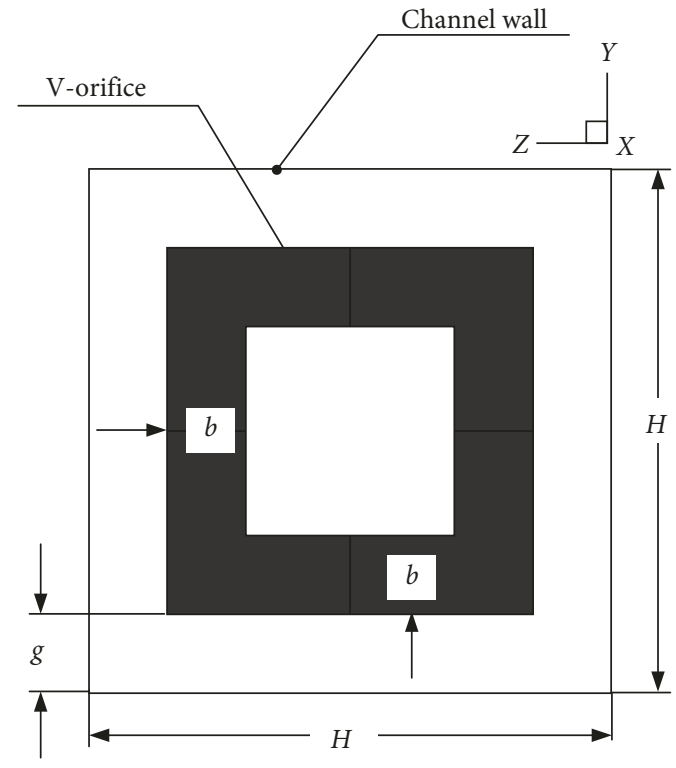

(b)

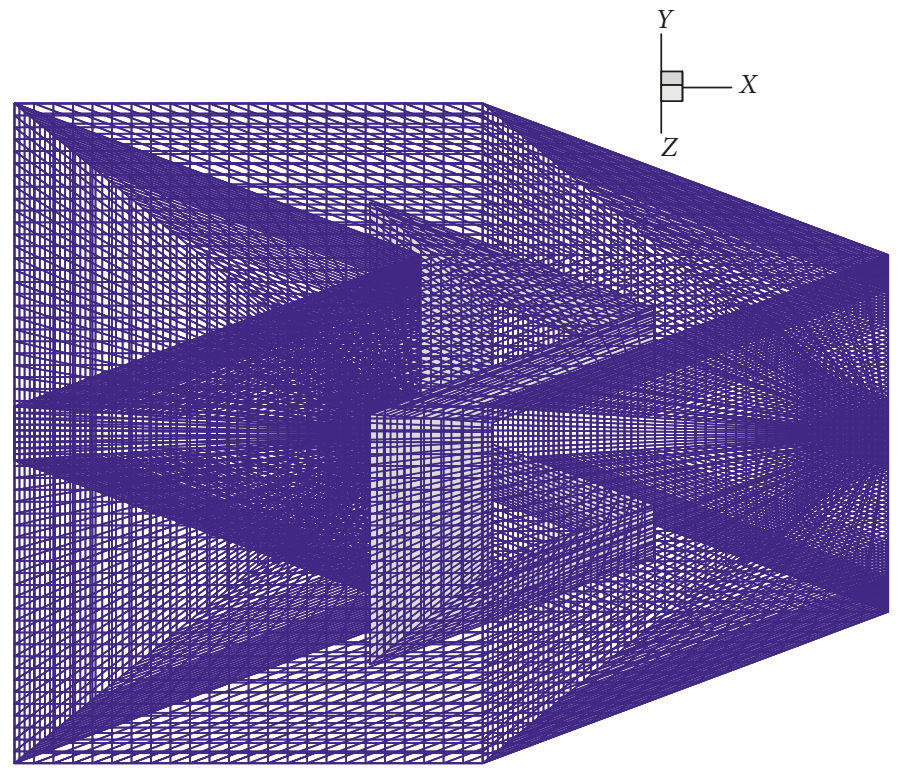

(c)

Figure 1: (a) Computational domain of the square channel heat exchanger installed with V-orifice. Numerical model in transverse plane (b) and with mesh (c).

and (8)). The thermal performance of the heating system is summarized with the thermal enhancement factor as follows:

$$
\operatorname{Re}=\frac{\rho \bar{u} D_{\mathrm{h}}}{\mu},
$$

where $D_{\mathrm{h}}$ is hydraulic diameter of the square channel heat exchanger.

$$
\begin{aligned}
f & =\frac{(\Delta P / L) D_{\mathrm{h}}}{(1 / 2) \rho \bar{u}^{2}}, \\
\mathrm{Nu}_{x} & =\frac{h_{x} D_{\mathrm{h}}}{k}, \\
\mathrm{Nu} & =\frac{1}{L} \int \mathrm{Nu}_{x} \partial x .
\end{aligned}
$$

The thermal enhancement factor (TEF) is defined as the ratio of the heat transfer coefficient of an augmented surface, $h$, to that of a smooth surface, $h_{0}$, at similar pumping power.

$$
\mathrm{TEF}=\left.\frac{h}{h_{0}}\right|_{\mathrm{pp}}=\left.\frac{\mathrm{Nu}}{\mathrm{Nu}_{0}}\right|_{\mathrm{pp}}=\frac{\left(\mathrm{Nu} / \mathrm{Nu}_{0}\right)^{(1 / 3)}}{\left(f / f_{0}\right)} .
$$

$\mathrm{Nu}_{0}$ and $f_{0}$ are the Nusselt number and friction factor for the smooth square channel, respectively.

\section{Validation of the Computational Domain}

The numerical validation is an important part for the numerical simulation. The validation result can confirm the reliability of the numerical result. The validation of the numerical model for the square channel inserted with $\mathrm{V}$-orifice can be divided into two parts: (1) grid independence and (2) verifications with the smooth channel for the Nusselt number and friction factor.

b15g15 of the numerical model is selected to check the grid independence. The hexahedral mesh with nonuniformity 
TABle 1: Case study.

\begin{tabular}{|c|c|}
\hline Case & Code \\
\hline$b / H=0.05, g / H=0$ & b05g0 \\
\hline$b / H=0.05, g / H=0.05$ & b05g05 \\
\hline$b / H=0.05, g / H=0.10$ & b05g10 \\
\hline$b / H=0.05, g / H=0.15$ & b05g15 \\
\hline$b / H=0.05, g / H=0.20$ & b05g20 \\
\hline$b / H=0.05, g / H=0.25$ & b05g25 \\
\hline$b / H=0.05, g / H=0.30$ & b05g30 \\
\hline$b / H=0.05, g / H=0.35$ & b05g35 \\
\hline$b / H=0.10, g / H=0$ & b10g0 \\
\hline$b / H=0.10, g / H=0.05$ & b10g05 \\
\hline$b / H=0.10, g / H=0.10$ & b10g10 \\
\hline$b / H=0.10, g / H=0.15$ & b10g15 \\
\hline$b / H=0.10, g / H=0.20$ & b10g20 \\
\hline$b / H=0.10, g / H=0.25$ & b10g25 \\
\hline$b / H=0.10, g / H=0.30$ & b10g30 \\
\hline$b / H=0.15, g / H=0$ & b15g0 \\
\hline$b / H=0.15, g / H=0.05$ & b15g05 \\
\hline$b / H=0.15, g / H=0.10$ & b15g10 \\
\hline$b / H=0.15, g / H=0.15$ & b15g15 \\
\hline$b / H=0.15, g / H=0.20$ & b15g20 \\
\hline$b / H=0.15, g / H=0.25$ & b15g25 \\
\hline$b / H=0.20, g / H=0$ & $\mathrm{~b} 20 \mathrm{~g} 0$ \\
\hline$b / H=0.20, g / H=0.05$ & b20g05 \\
\hline$b / H=0.20, g / H=0.10$ & $\mathrm{~b} 20 \mathrm{~g} 10$ \\
\hline$b / H=0.20, g / H=0.15$ & b20g 15 \\
\hline$b / H=0.20, g / H=0.20$ & b20g20 \\
\hline$b / H=0.25, g / H=0$ & $\mathrm{~b} 25 \mathrm{~g} 0$ \\
\hline$b / H=0.25, g / H=0.05$ & b25g05 \\
\hline$b / H=0.25, g / H=0.10$ & $\mathrm{~b} 25 \mathrm{~g} 10$ \\
\hline$b / H=0.25, g / H=0.15$ & $\mathrm{~b} 25 \mathrm{~g} 15$ \\
\hline$b / H=0.30, g / H=0$ & b30g0 \\
\hline$b / H=0.30, g / H=0.05$ & b30g05 \\
\hline$b / H=0.30, g / H=0.10$ & b30g10 \\
\hline
\end{tabular}

TABLE 2: Boundary condition and initial condition.

\begin{tabular}{lc}
\hline Zone & Boundary condition/initial condition \\
\hline Inlet & Periodic boundary \\
Outlet & Periodic boundary \\
Channel wall & Uniform temperature at $310 \mathrm{~K}$ \\
V-orifice & No slip wall \\
& Insulator \\
& No slip wall \\
\hline
\end{tabular}

is applied for all investigated cases. The different numbers of grid, 120000, 240000, 360000, 440000, and 600000, are applied for the numerical model. It is found that the increment of cells from 240000 to 360000 has no effect for both Nusselt number and friction loss. The deviations for both values are found to be around $\pm 0.2 \%$. Therefore, the grid cell around 240000 is created for all investigated cases when considered by both time for investigation and accuracy result.

The verifications of the smooth channel with no orifice for heat transfer and pressure loss are plotted as Figure 2. The results from the present prediction are compared with the results from the correlations [17]. The heat transfer rate is presented with the Nusselt number, $\mathrm{Nu}_{0}$, while the pressure loss is offered in term of friction factor, $f_{0}$. As the figure, the

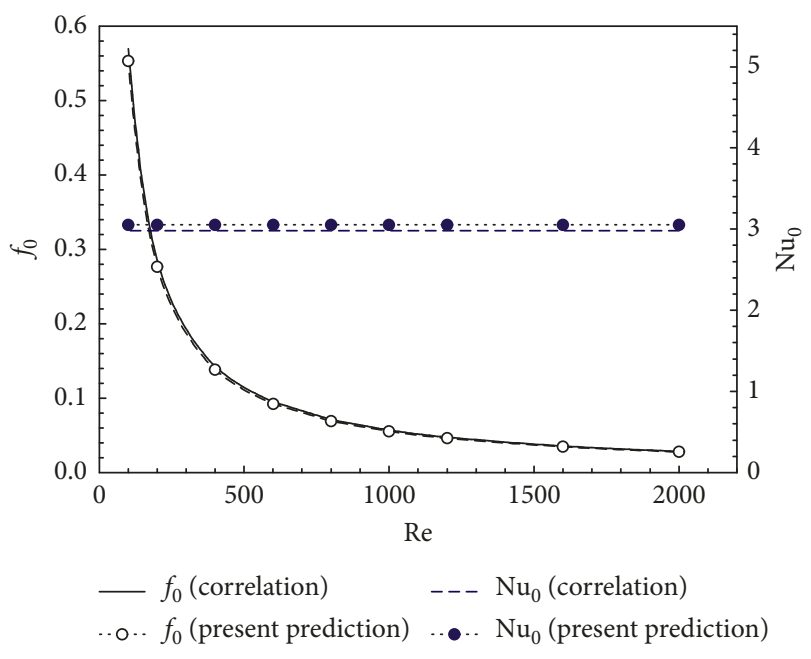

FIgURE 2: Validation of the smooth channel on Nusselt number and friction factor.

deviations of the Nusselt number and friction factor are around $\pm 2.4 \%$ and $\pm 3.0 \%$, respectively.

As the results above, it can be concluded that the creation domain has enough reliability to predict flow and heat transfer mechanisms in the heat exchanger square channel inserted with $\mathrm{V}$-orifice.

\section{Numerical Result and Discussion}

7.1. Influence of Blockage Ratio and Gap Spacing Ratio. The flow configurations in the heat exchanger channel fitted with various parameters of the $\mathrm{V}$-orifice are presented by streamline in transverse planes and longitudinal vortex flow through the test section. The streamline in transverse planes at $x / D=0.5$ in the square channel with $\mathrm{V}$-orifice is depicted as Figure 3 for $\mathrm{V}$-downstream arrangement. It is found that the $\mathrm{V}$-orifice can generate the vortex flow in all investigated cases. In general, the four main vortex flows are detected. The symmetry flow for left-right parts and upper-lower parts is found due to the symmetry configuration of the $\mathrm{V}$-orifice. The small vortices at four corners of the channel are also detected in all cases. The vortex core has change depended on the position in the test section, blockage ratio, and gap spacing ratio. The vortex flow in the test section helps to improve the fluid mixing and the distribution of the fluid temperature between core of the channel and near the channel walls. The vortex flow also disturbs the thermal boundary layer on the heat transfer surface. These behaviors are causes for heat transfer and thermal performance augmentations. The strength of the vortex flow directly affects the enhancement of the heat transfer rate and thermal performance.

Figures 4(a) and 4(b) report the longitudinal vortex flow of the square channel heat exchanger fitted with $\mathrm{V}$-orifice at $\mathrm{Re}=600$ and $\mathrm{V}$-downstream arrangement for b15g0 (no gap) and b15g15 (with gap), respectively. The longitudinal vortex flow is found through the test section on both cases. The flow configuration is found to be in nearly pattern. Some parts of the air flow pass the gap between the orifice and the 


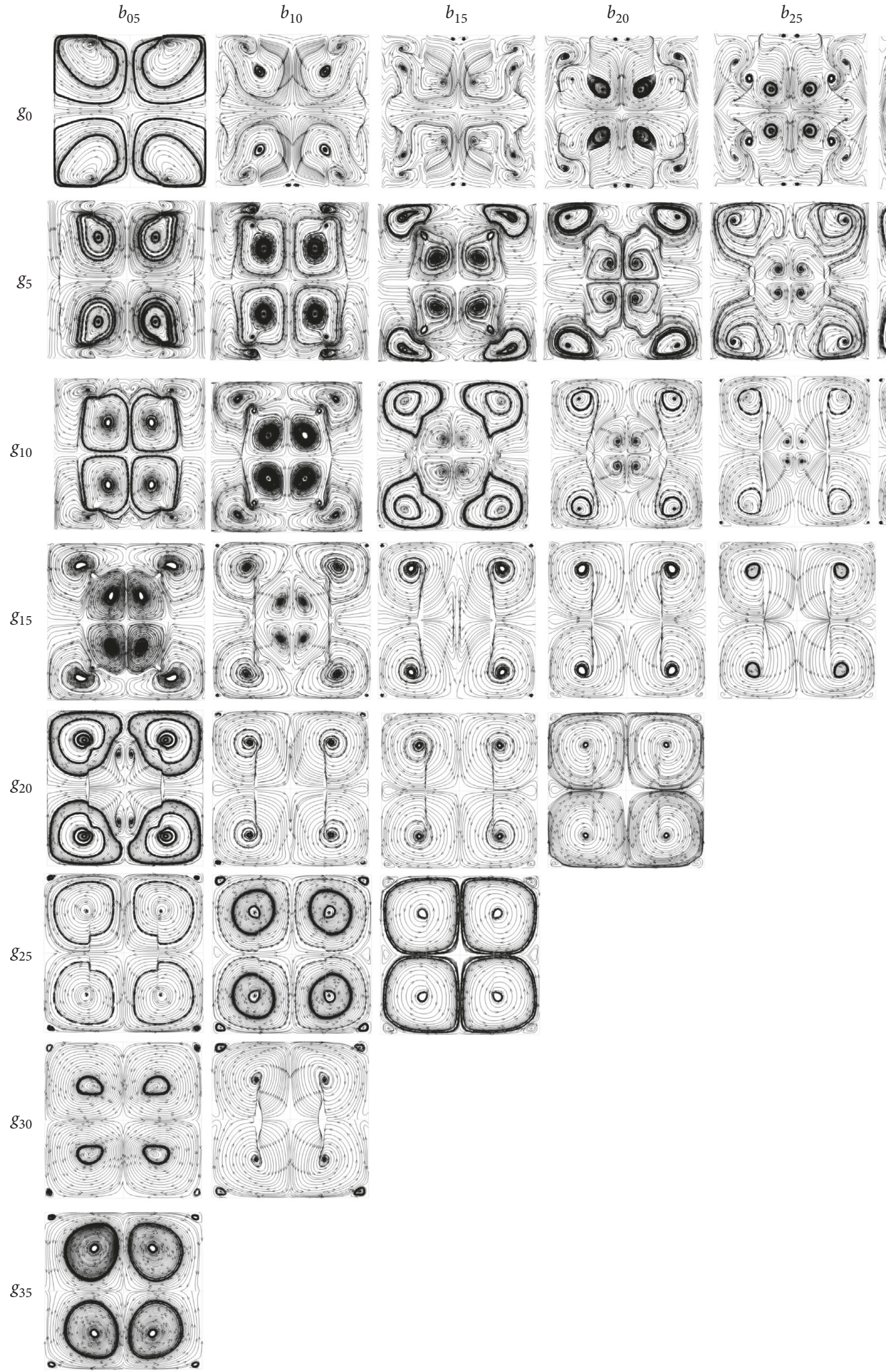

FIGURE 3: Streamlines in transverse planes for the square channel heat exchanger installed with V-orifice at various blockage ratios and gap spacing ratios for $\mathrm{Re}=800$ and $\mathrm{V}$-downstream arrangement.

channel wall in the case of b15g15. The optimum gap spacing can help to reduce the pressure loss and also increase the strength of the vortex flow.
The heat transfer characteristics in the square channel placed with $\mathrm{V}$-orifice at various parameters are reported in forms of temperature distributions in transverse planes and 


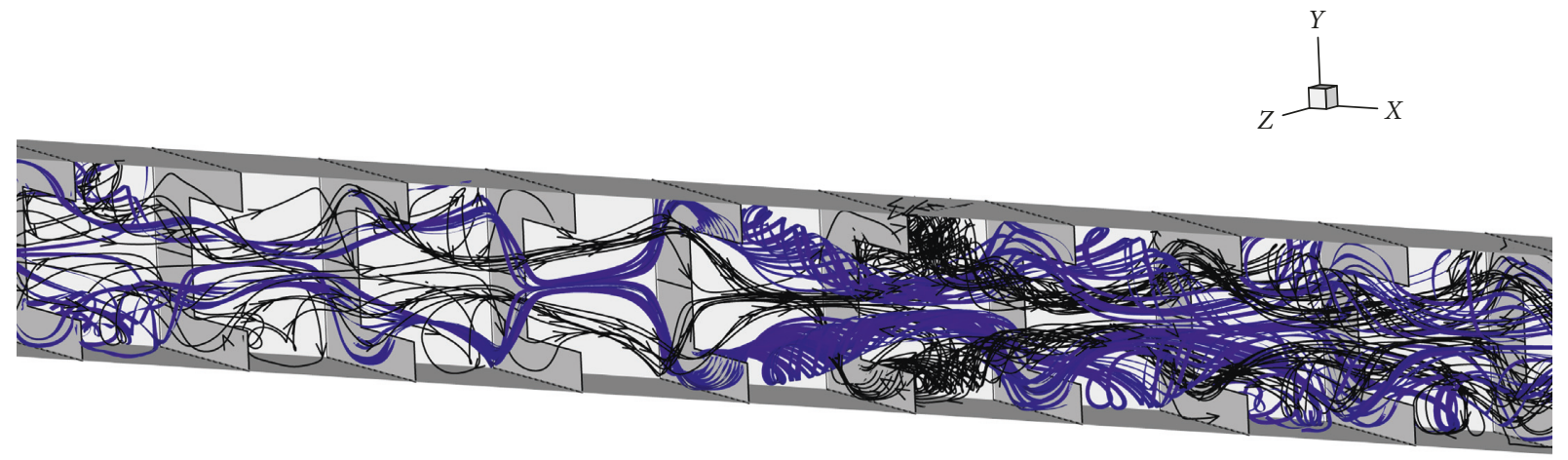

(a)

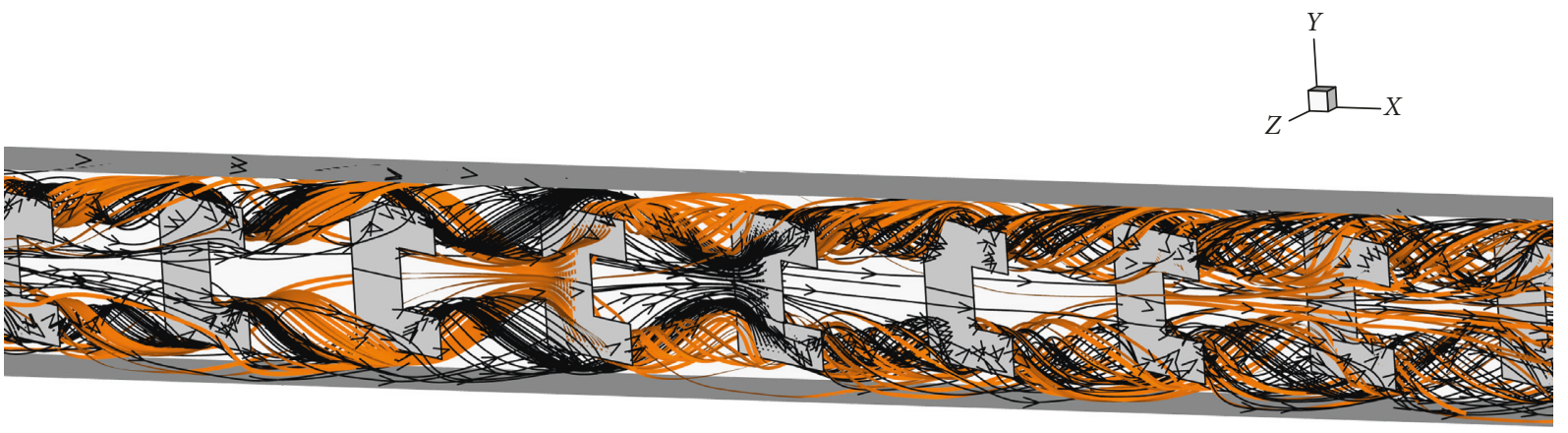

(b)

FiguRE 4: Longitudinal vortex flow for the square channel heat exchanger installed with V-orifice at (a) b15g0 and (b) b15g10 for Re $=800$ and V-downstream arrangement.

local Nusselt number on the heat transfer surface. Figure 5 illustrates the temperature distributions in transverse planes for the square duct inserted with $\mathrm{V}$-orifice at various flow blockage ratios and gap spacing ratios. In general, the low temperature of the fluid (blue layer) is detected at core of the square channel, while the high fluid temperature (red layer) is found near the channel walls for the smooth channel with no orifice. The insertion of the $\mathrm{V}$-orifice in the channel changes the heat transfer behavior. The thermal boundary layer near the channel walls is disturbed by the vortex flow, which is generated by the $\mathrm{V}$-orifice in all cases. The red layer near the channel walls is found to be thinner, while the blue layer distributes from the center of the channel.

The local Nusselt number for the heat exchanger square channel placed with $\mathrm{V}$-orifice at various cases is plotted as Figure 6 for $\mathrm{V}$-downstream arrangement. The increment of the flow blockage ratio of the $\mathrm{V}$-orifice performs higher heat transfer rate in all gap spacing ratios. The worst heat transfer area is clearly found at behind the $\mathrm{V}$-orifice when $\mathrm{g} / \mathrm{H}=0$ (no gap). The gap spacing ratio helps to increase heat transfer rate, especially, at behind the $\mathrm{V}$-orifice, but the strength of the vortex flow seems to be decrease at high gap spacing ratio.

7.2. Influence of Flow Direction. The influences of the V-tip arrangement for the $\mathrm{V}$-orifice in the heat exchanger channel are presented by both flow configuration and heat transfer characteristic. The streamline in transverse plane in the square channel placed with $\mathrm{V}$-orifice at various blockage ratios, gap spacing ratios, and arrangement is shown in Figure 7. The four to eight main vortex flows is detected in all cases. The augmentation on the number of the vortex core helps to distribute the temperature of the fluid flow in the test section, but the strength of the vortex flow may decrease. The different arrangement of the $\mathrm{V}$-orifice directly affects the rotational direction of the vortex flow. The V-downstream arrangement gives the opposite rotation of the vortex flow when compared with the $\mathrm{V}$-upstream arrangement.

Figures 8(a) and 8(b) report the longitudinal vortex flow of the square channel inserted with $\mathrm{V}$-orifice for $\mathrm{V}$-downstream and $\mathrm{V}$-upstream arrangements, respectively. The longitudinal vortex flow is found through the test section on both examples. Some parts of the air flows pass the gap between the channel wall and the edges of the $\mathrm{V}$-orifice. This behavior may help to enhance the turbulent mixing of the air flow and also reduce the pressure drop across the test section.

The heat transfer behaviors in the heat exchanger channel fitted with the $\mathrm{V}$-orifice are plotted in forms of the temperature distribution in transverse planes and the local Nusselt number distribution on the heat transfer surface as depicted in Figures 9 and 10, respectively. The temperature distribution in transverse planes is an indicator to check the change of the thermal boundary layer on the heat transfer surface (channel wall). Generally, the low temperature and high temperature of the fluid are found at the core of the channel and near the channel walls, respectively. The 

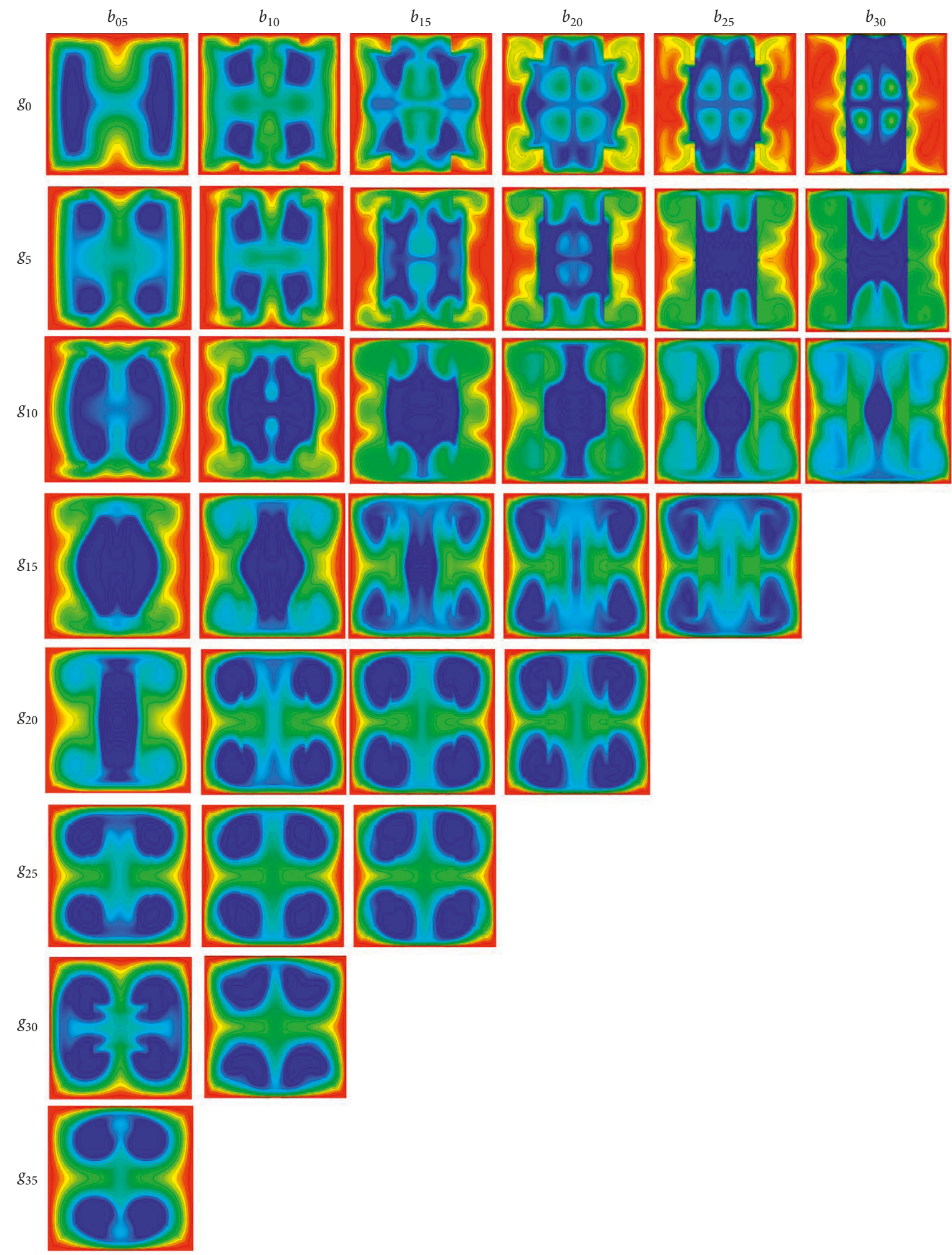

Temperature

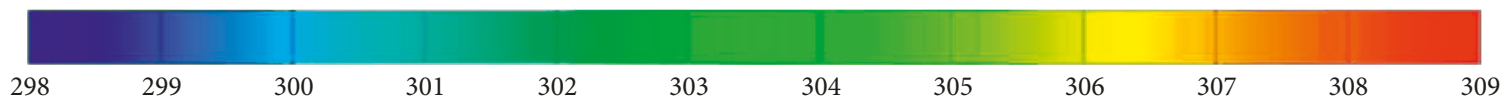

FIGURE 5: Temperature distribution in transverse planes for the square channel heat exchanger installed with V-orifice at various blockage ratios and gap spacing ratios for $\mathrm{Re}=800$ and $\mathrm{V}$-downstream arrangement. 


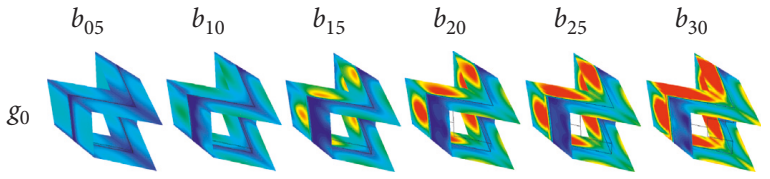

Nusselt number

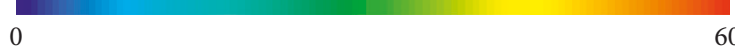

$g_{5}$

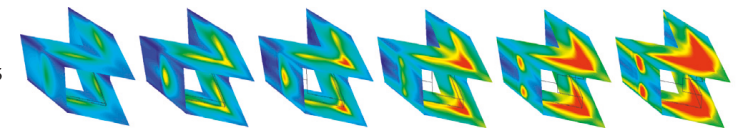

Nusselt number

0

50

$g_{10}$

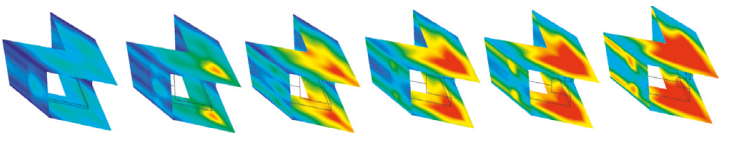

Nusselt number

0

50

$g_{15}$

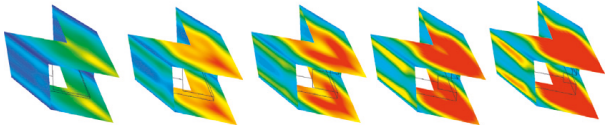

Nusselt number

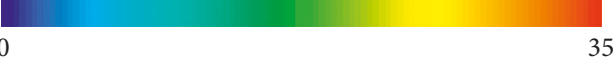

$g_{20}$

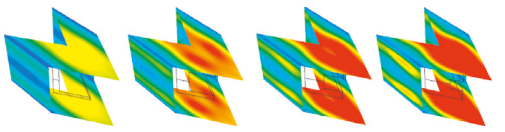

Nusselt number
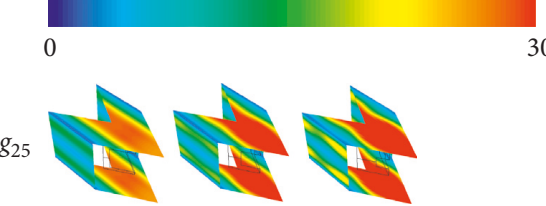

Nusselt number
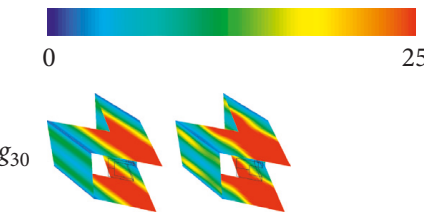

Nusselt number
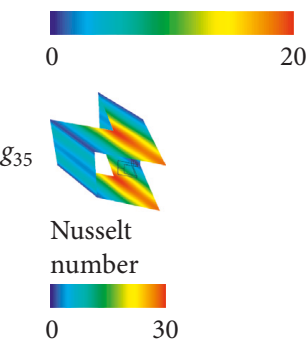

Figure 6: Local Nusselt number distribution on the channel walls for the square channel heat exchanger installed with $\mathrm{V}$-orifice at various blockage ratios and gap spacing ratios for $\mathrm{Re}=800$ and $\mathrm{V}$ downstream arrangement. installation of the V-orifice in the heat exchanger channel has an effect for the change of the temperature distribution and thermal boundary layer. The better mixing of the fluid flow is found, while the thermal boundary layer is disturbed. The perturbation of the thermal boundary layer on each side of the heat transfer surface is not similar when the arrangement of the V-orifice is changed. The severe disturbance of the thermal boundary is found at the upper-lower sides of the channel for the V-downstream arrangement, while it is detected at the left-right sidewalls of the channel in the case of the $\mathrm{V}$-upstream arrangement. Therefore, the peak of heat transfer rate is found at the upper-lower walls of the channel for the V-Downstream arrangement, while it is detected at the left-right sidewalls of the channel for the V-upstream arrangement (Figure 10).

7.3. Performance Analysis. The performance assessments in the heat exchanger square channel placed with the $\mathrm{V}$-orifice are shown in terms of the Nusselt number ratio $\left(\mathrm{Nu} / \mathrm{Nu}_{0}\right)$, friction factor ratio $\left(f / f_{0}\right)$, and thermal enhancement factor (TEF). The relations of the $\mathrm{Nu} / \mathrm{Nu}_{0}$ with the Reynolds number for the square channel heat exchanger inserted with the V-orifice are depicted in Figures 11(a)-11(f), respectively, for b5, b10, b15, b20, b25, and b30 at V-downstream arrangement. In general, the heat transfer coefficient increases when enhancing the Reynolds number for all examples. The insertion of the V-orifice in the heat exchanger square channel provides higher heat transfer rate than the smooth square channel with no orifice $(\mathrm{Nu} /$ $\mathrm{Nu}_{0}>1$ ). The peak of heat transfer rate is found at $\mathrm{Re}=2000$, while the opposite trend is found at $\mathrm{Re}=100$. Considering $\mathrm{Re}=2000$, the highest heat transfer rate for the b05, b10, and b15 is found at g20, g25, and g10, respectively, while g0 performs the best heat transfer rate for b20-b30. Nu/Nu $\mathrm{Nu}_{0}$ is around 1.00-5.52, 0.90-5.98, 1.00-11.62, 1.27-13.63, 1.5518.35, and 2.14-28.16, respectively, for b5, b10, b15, b20, $\mathrm{b} 25$, and b30, at V-downstream arrangement.

Figure 12 presents the relations of $\mathrm{Nu} / \mathrm{Nu}_{0}$ with the Reynolds number for the heat exchanger channel inserted with the $\mathrm{V}$-orifice at $\mathrm{V}$-tip pointing upstream. The similar trend as the V-downstream arrangement is detected; the heat transfer rate increases when increasing the Reynolds number. At b05, the peak of heat transfer rate is found at $g / H$ around $15-20 \%$. The maximum heat transfer coefficient for b10 is found at $\mathrm{g} 05$. When $g / H>10 \%$, the maximum values of the Nusselt number ratio is found at $\mathrm{g} 0$. The installation of the $\mathrm{V}$-upstream orifice gives the heat transfer rate around $0.88-5.08,1.00-8.89$, $1.00-12.88,1.32-14.10,2.00-18.49$, and 2.20-26.93 times higher than the smooth channel with no orifice for b05, b10, b15, b20, b25, and b30, respectively, at $R e=100-2000$.

The pressure loss in the heat exchanger channel is presented with the friction factor values. The variation of the friction factor ratio for the channel fitted with various parameters of the V-downstream orifice is illustrated in Figure 13 . As seen in the figure, $f l f_{0}$ enhances when augmenting the Reynolds number for all investigated examples. The maximum and minimum values of $f / f_{0}$ are found at the 

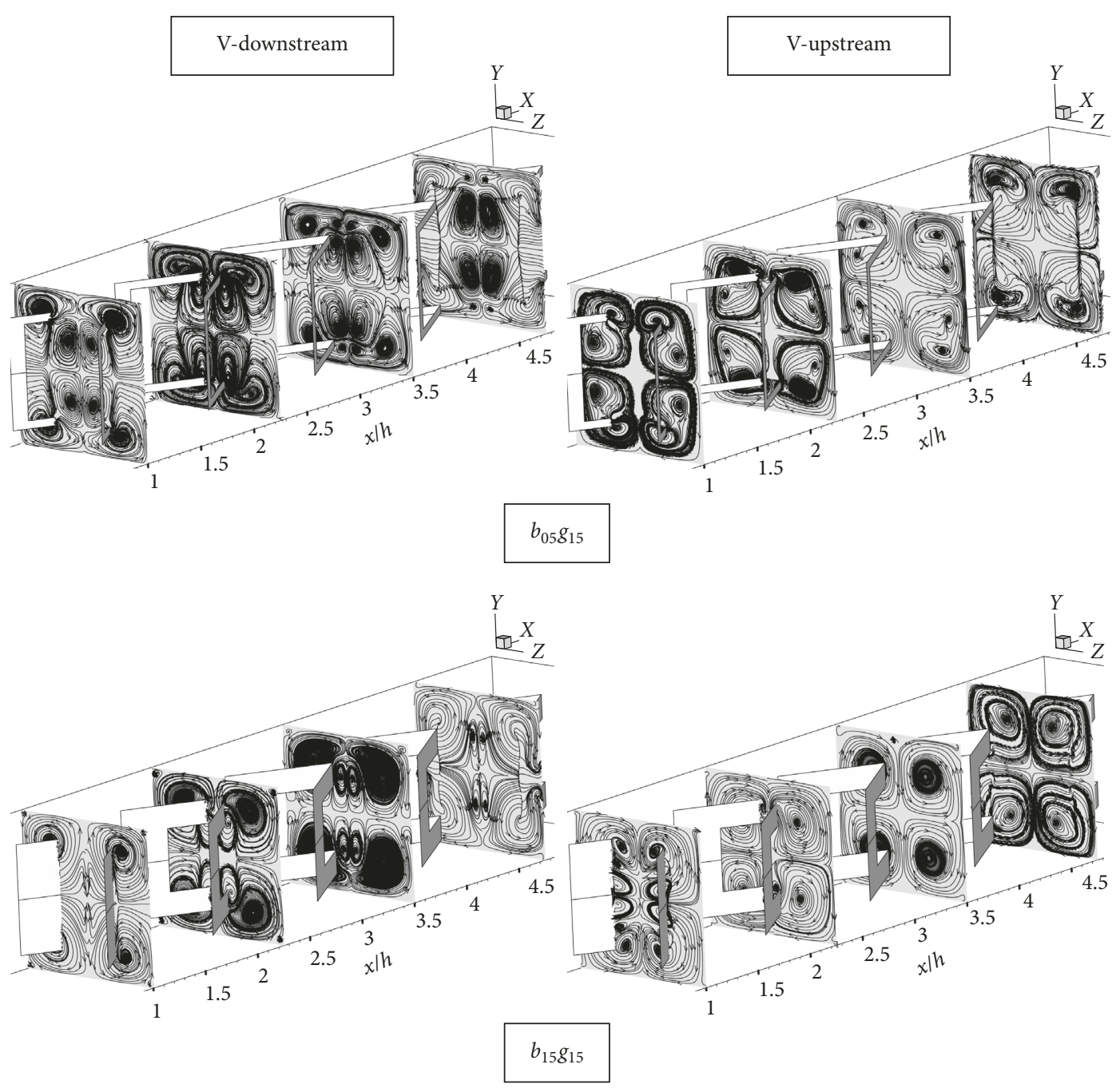

FIGURE 7: Streamlines in transverse planes for the square channel heat exchanger installed with V-orifice at various blockage ratios and flow direction for $\mathrm{Re}=600$ and $\mathrm{V}$-downstream arrangement.

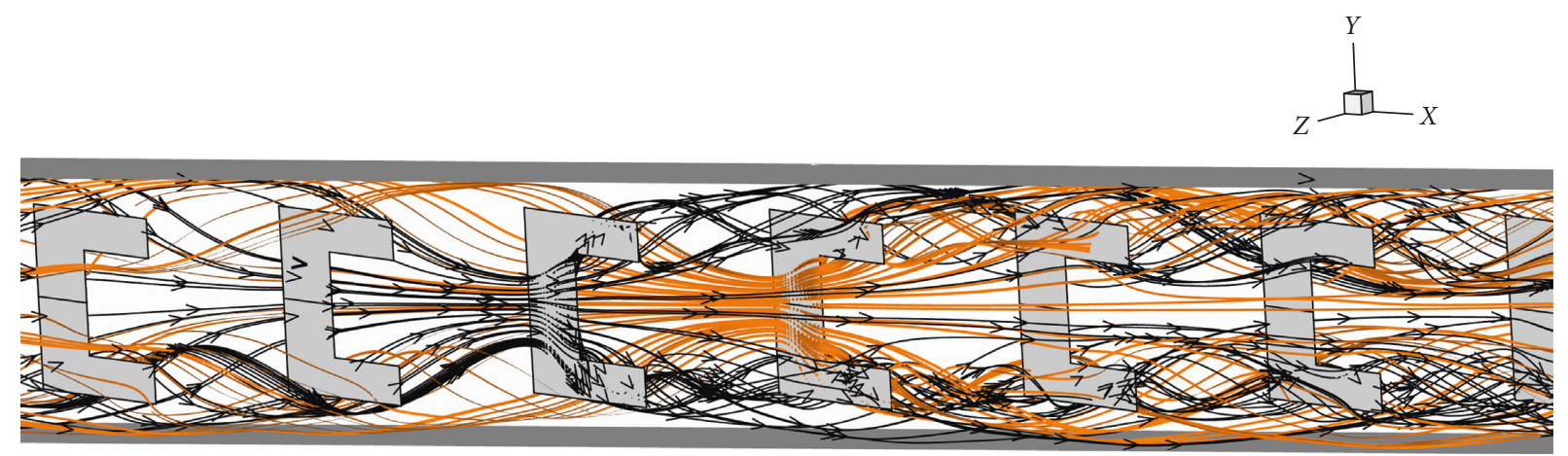

(a)

Figure 8: Continued. 


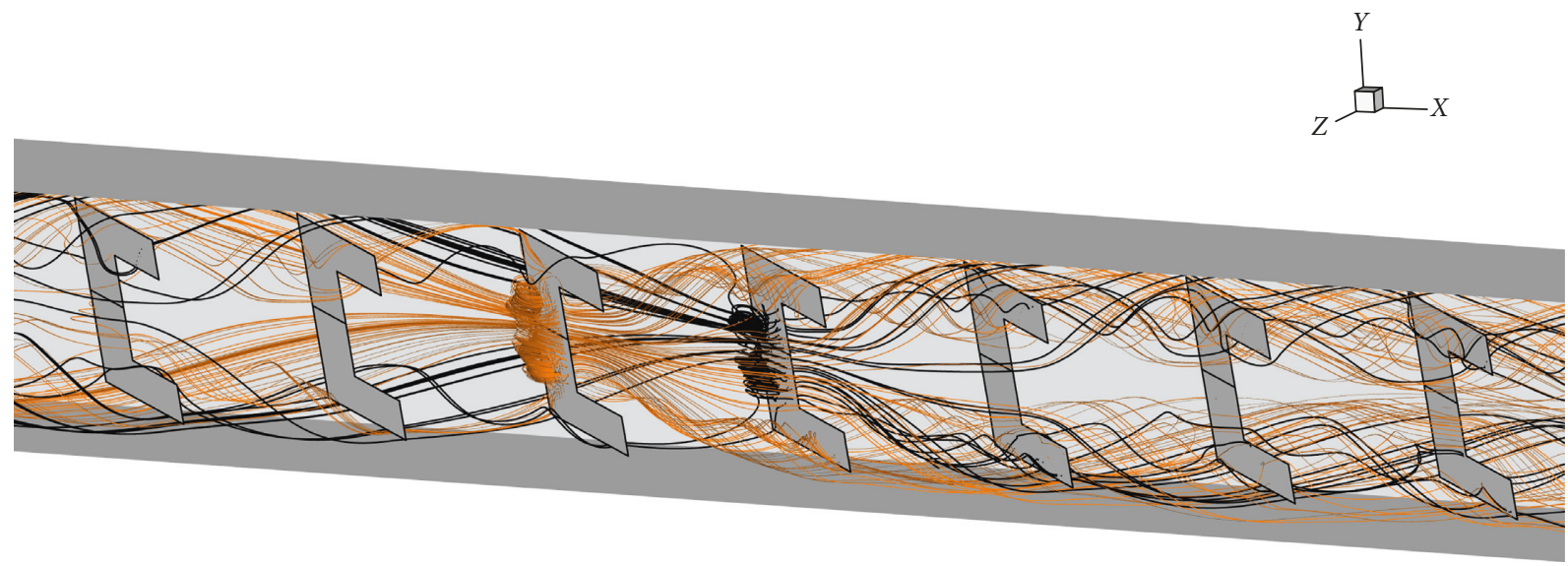

(b)

FIGURE 8: Longitudinal vortex flow for the square channel heat exchanger installed with V-orifice at (a) V-downstream and (b) V-upstream for $\mathrm{b} 15 \mathrm{~g} 15$ and $\mathrm{Re}=600$.
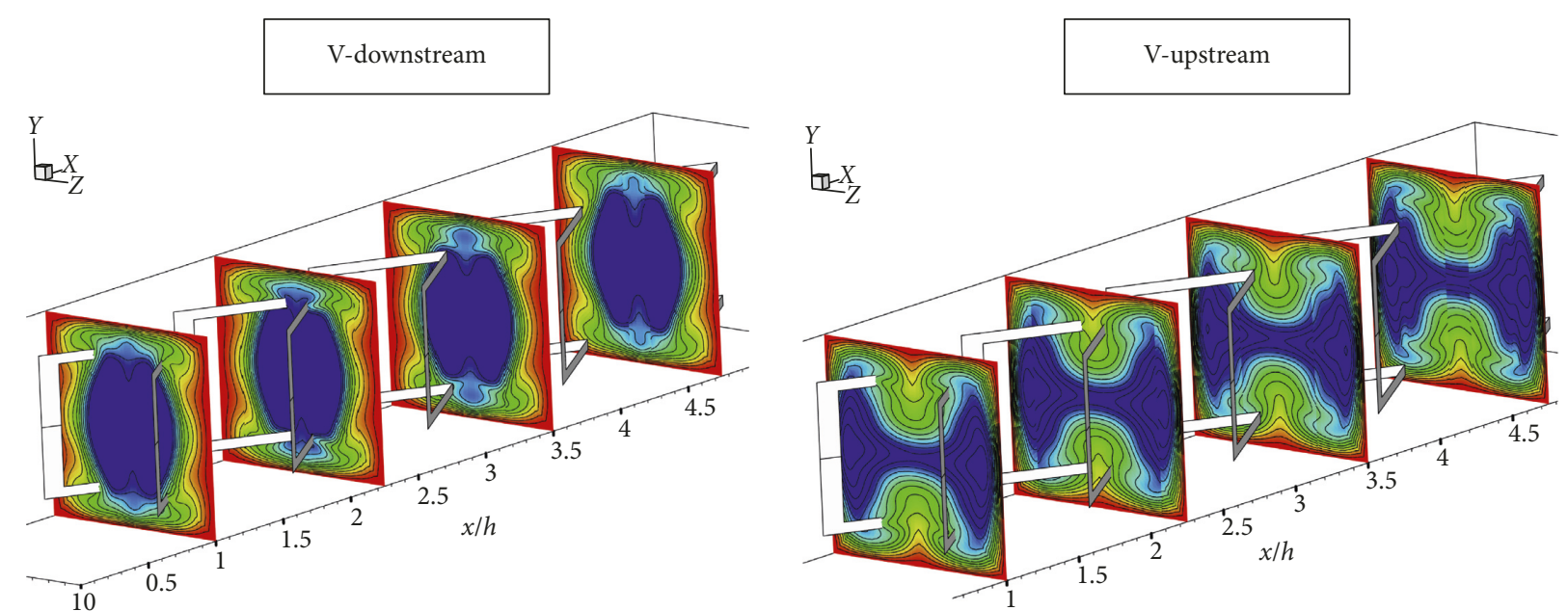

Temperature

Temperature

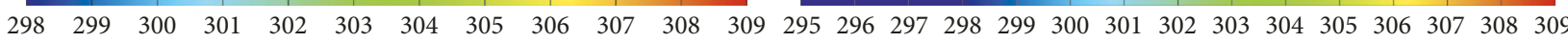

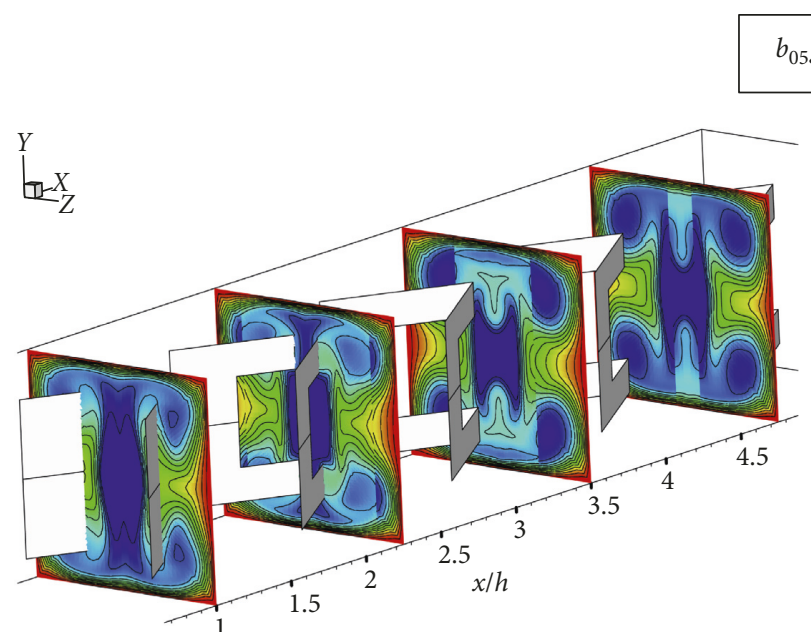

Temperature

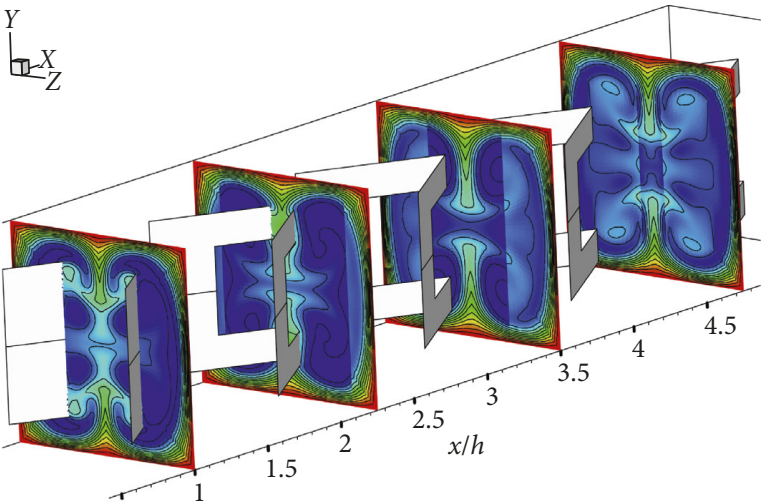

Temperature

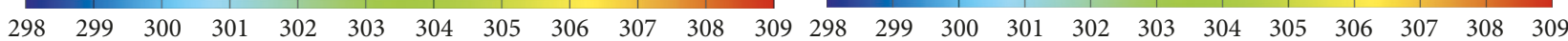

$$
b_{15} g_{15}
$$

FIGURE 9: Temperature distribution in transverse planes for the square channel heat exchanger installed with V-orifice at various blockage ratios and flow direction for $\mathrm{Re}=600$ and $\mathrm{V}$-downstream arrangement. 


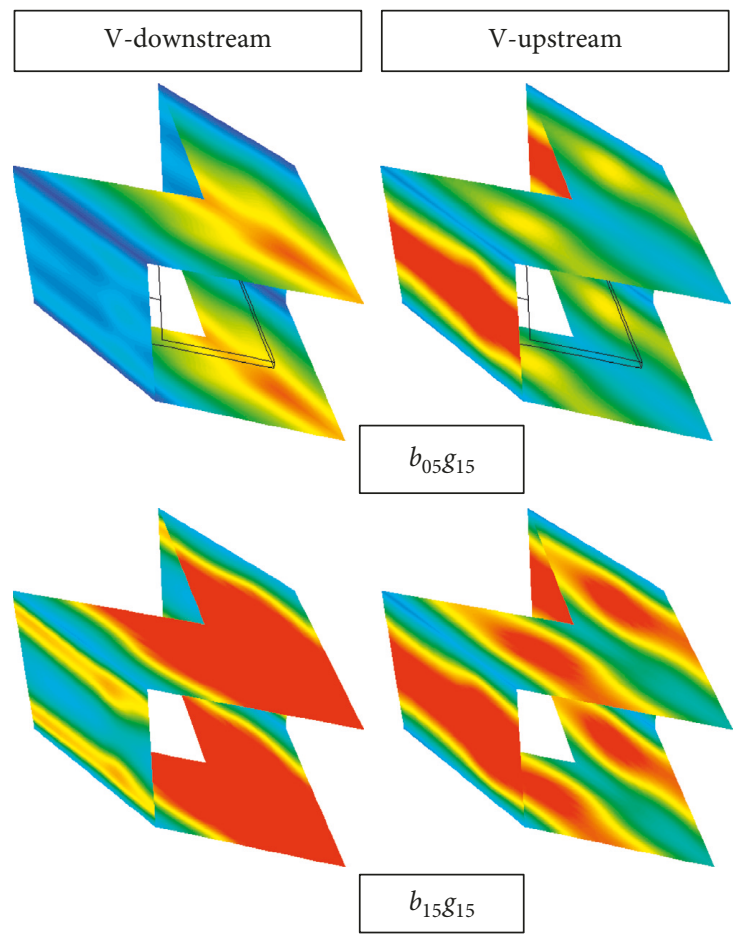

Nusselt number

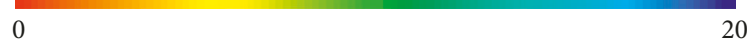

FIGURE 10: Local Nusselt number distribution on the channel walls for the square channel heat exchanger installed with V-orifice at various blockage ratios and flow direction for $\mathrm{Re}=600$ and $\mathrm{V}$-downstream arrangement.
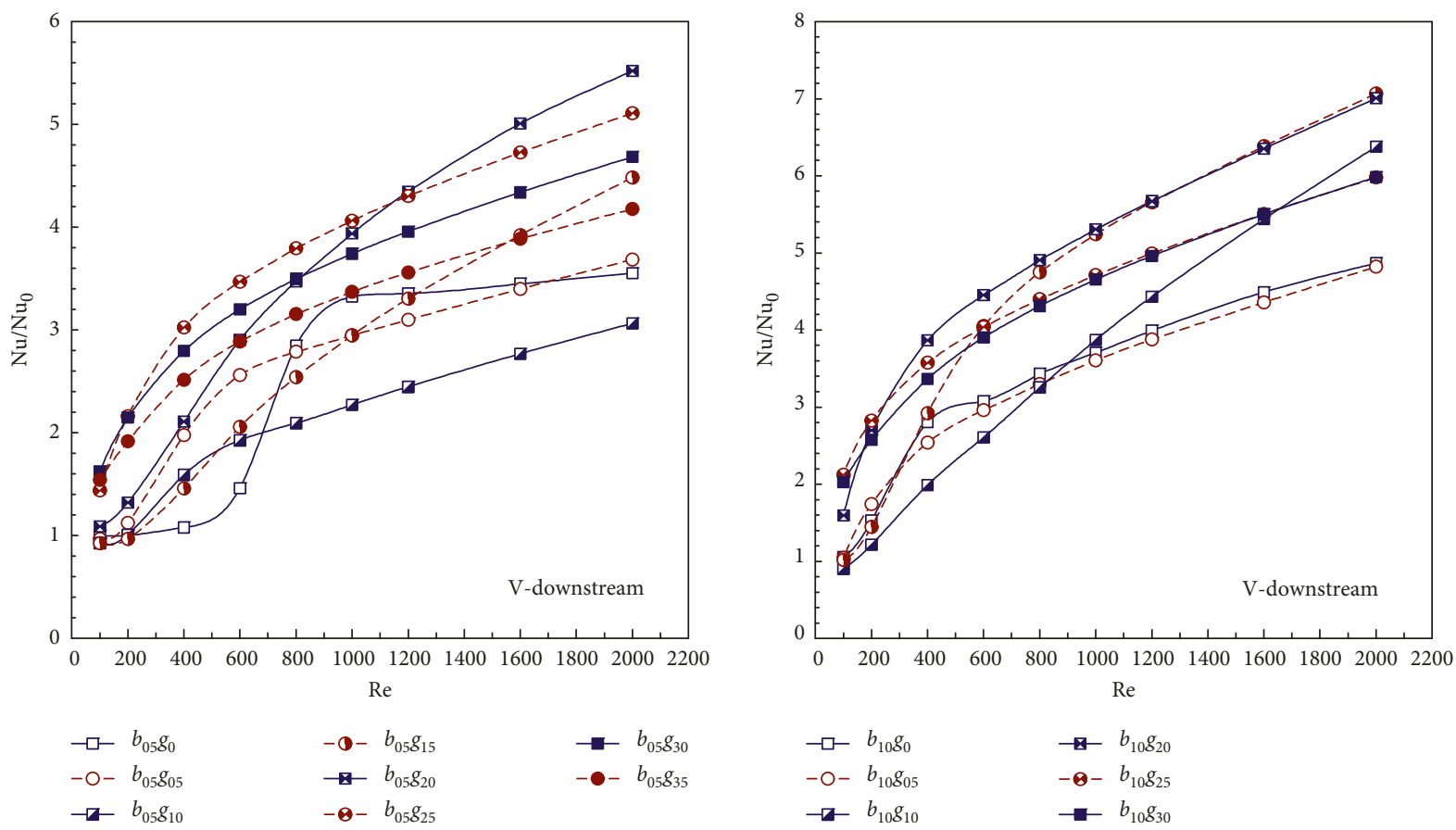

$$
\begin{array}{ll}
-\square- & b_{10} g_{0} \\
-\bigcirc- & b_{10} g_{05} \\
-\boldsymbol{Z} & b_{10} g_{10} \\
-\bullet- & b_{10} g_{15}
\end{array}
$$$$
\rightarrow-b_{10} g_{20}
$$$$
\text { -8- } b_{10} g_{25}
$$

(a)

(b)

Figure 11: Continued. 


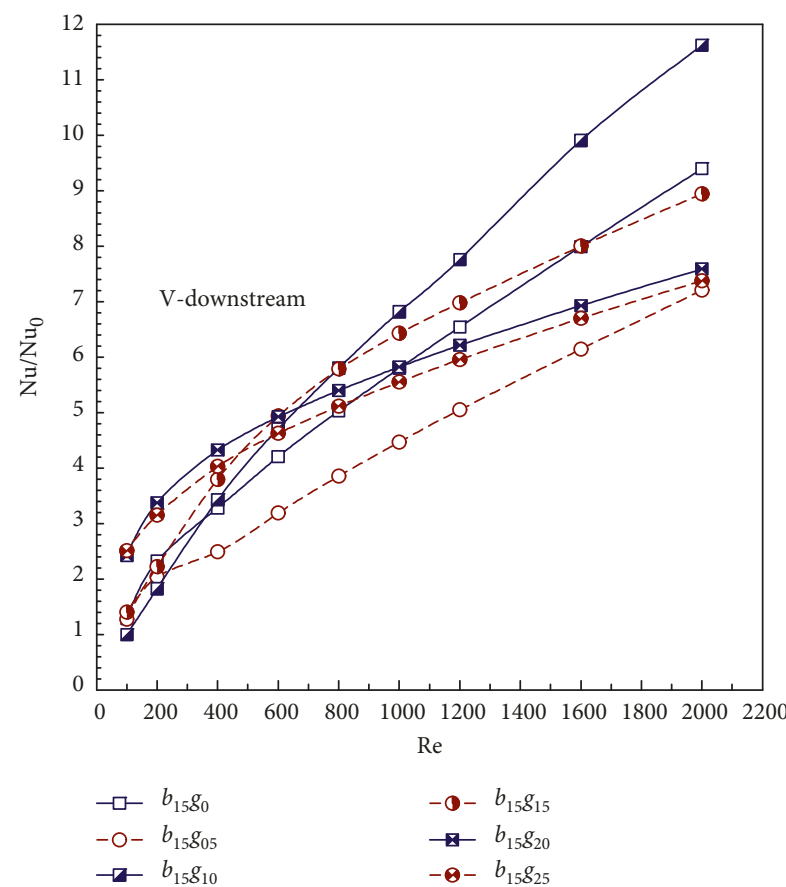

(c)

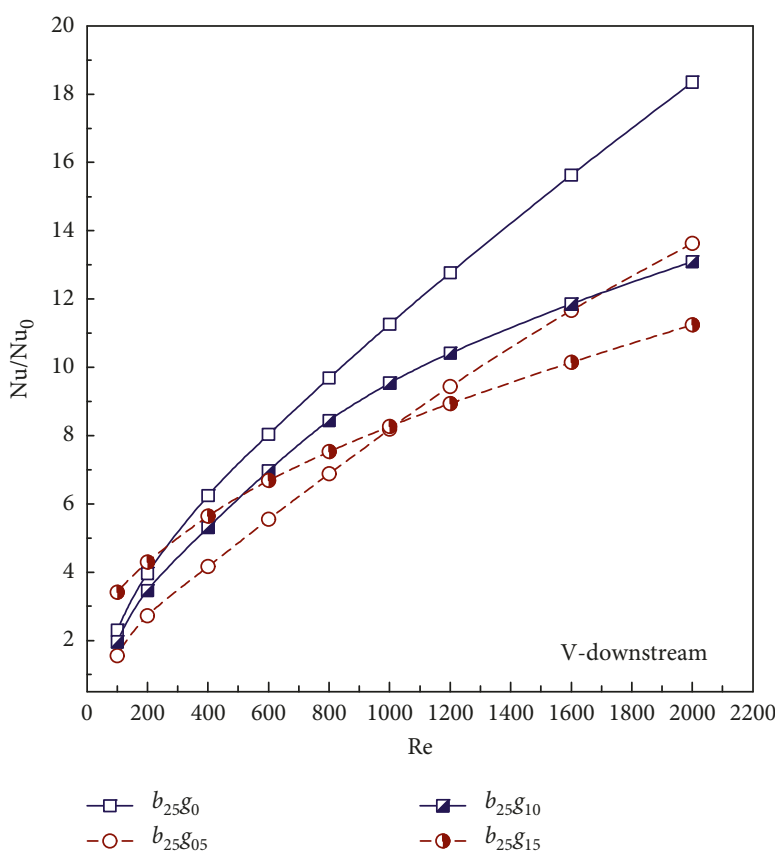

(e)

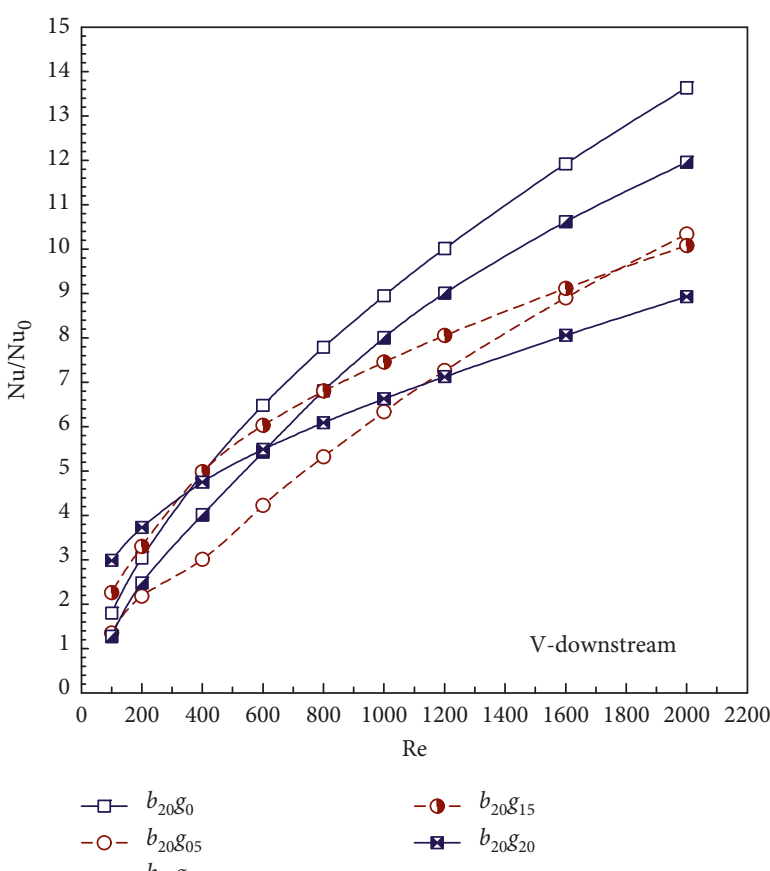

(d)

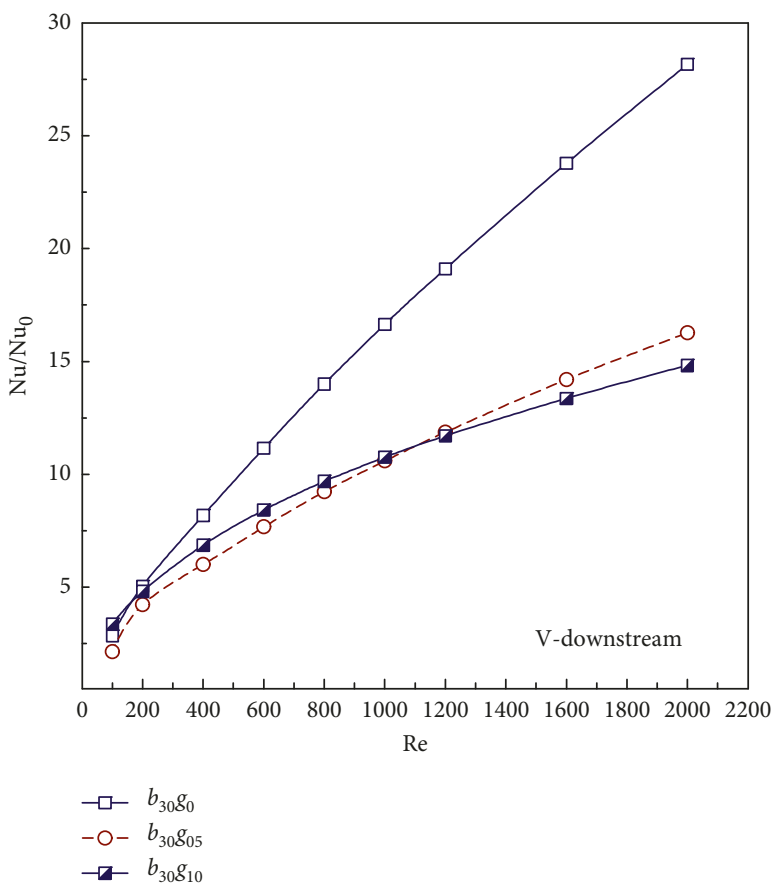

(f)

Figure 11: Relation of $\mathrm{Nu} / \mathrm{Nu}_{0}$ with the Reynolds number for (a) b05, (b) b10, (c) b15, (d) b20, (e) b25, and (f) b30 at V-downstream arrangement.

$\operatorname{Re}=2000$ and 100, respectively. The presence of the V-orifice in the heat exchanger channel not only increases in heat transfer rate but also increases in the pressure loss. The friction loss of the channel with $\mathrm{V}$-orifice is higher than the smooth channel in all studied cases $\left(f / f_{0}>1\right)$. The peak of friction loss is found at g20 and g10 for b05 and b10, respectively, while found at g0 when $b / H>0.1$. $f / f_{0}$ is around 1.00-9.12, 1.90-
$19.65,3.64-51.41,6.28-153.22,9.93-444.14$, and $18.68-$ 1309.53, respectively, for b05, b10, b15, b20, b25, and b30.

The similar trend of $f / f_{0}$ is found in the case of $\mathrm{V}$-upstream arrangement as depicted in Figure 14. g15 and g5 of b05 and b10, respectively, perform the maximum heat transfer rate when compared at similar blockage ratio. When $b / H>10 \%$, $g / H=0$ brings the uppermost friction loss at similar 


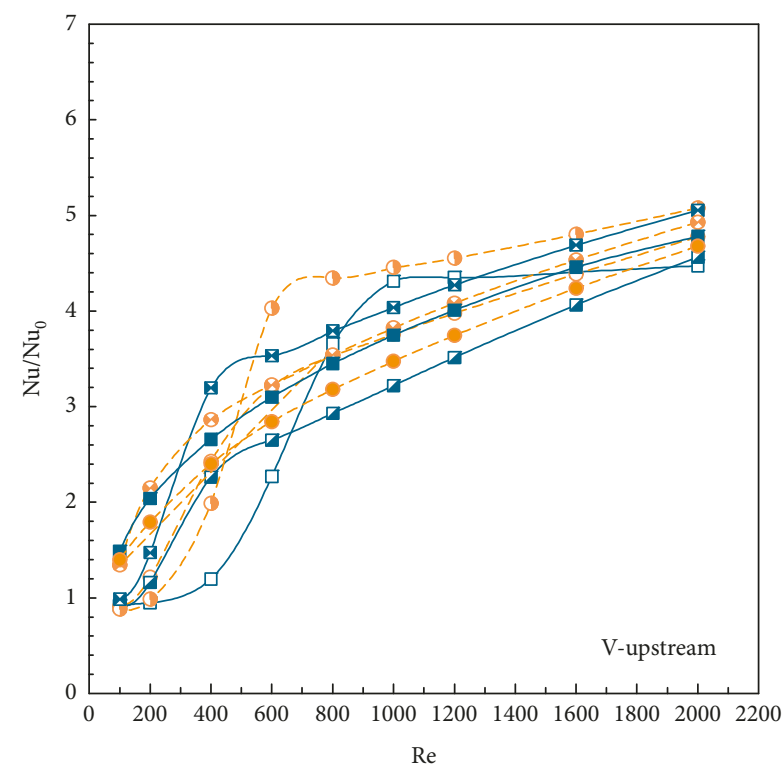

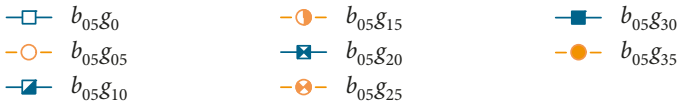

(a)

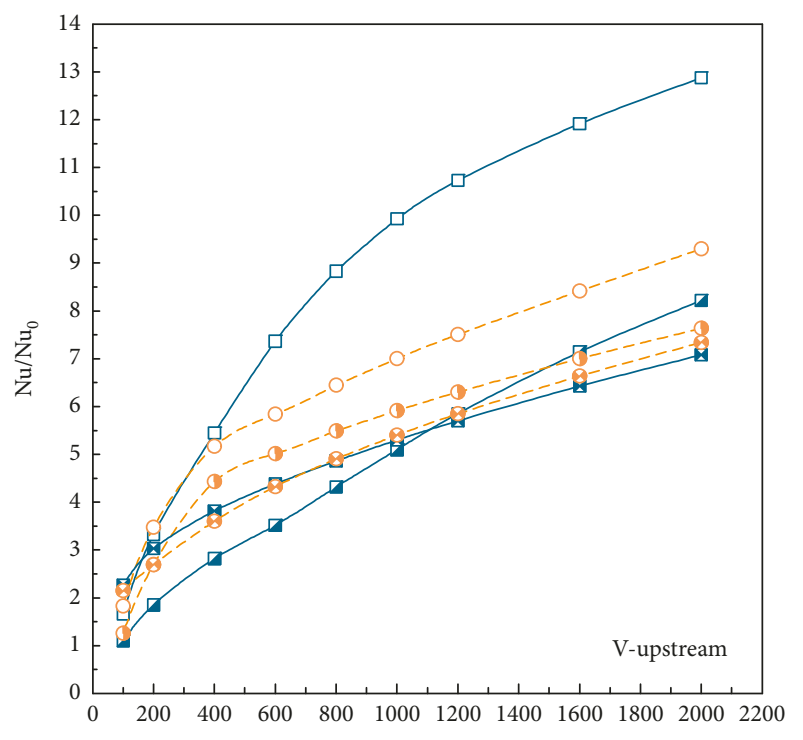

Re
$-\square-b_{15} g_{0}$
$-\bigcirc-b_{15} g_{05}$
$-\square-b_{15} g_{10}$

$$
-0-b_{15} g_{15}
$$

(c)

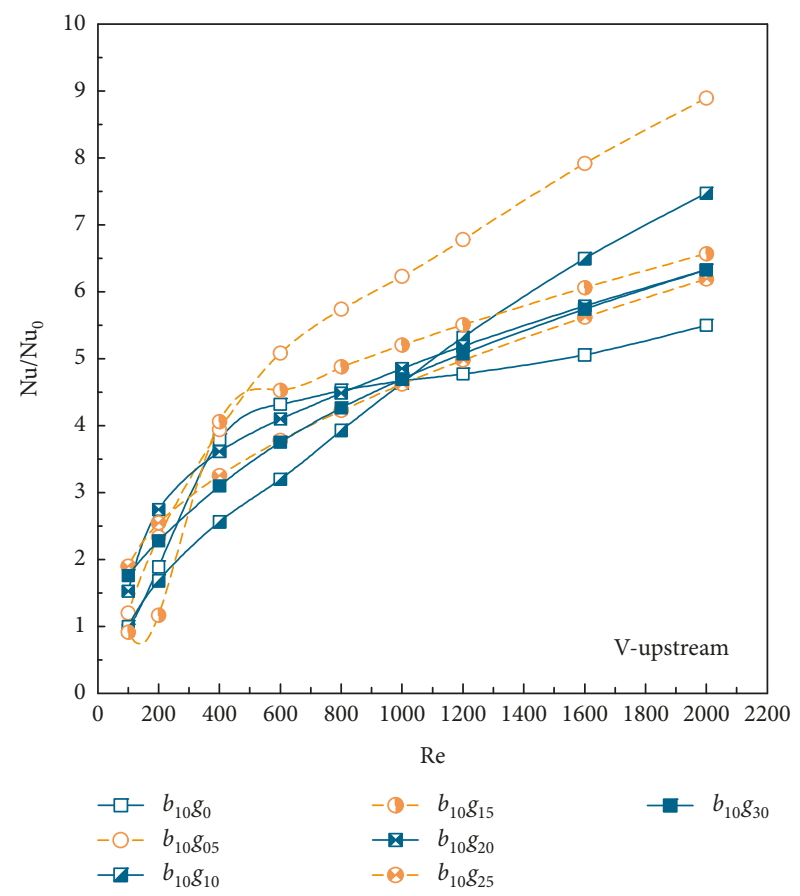

(b)

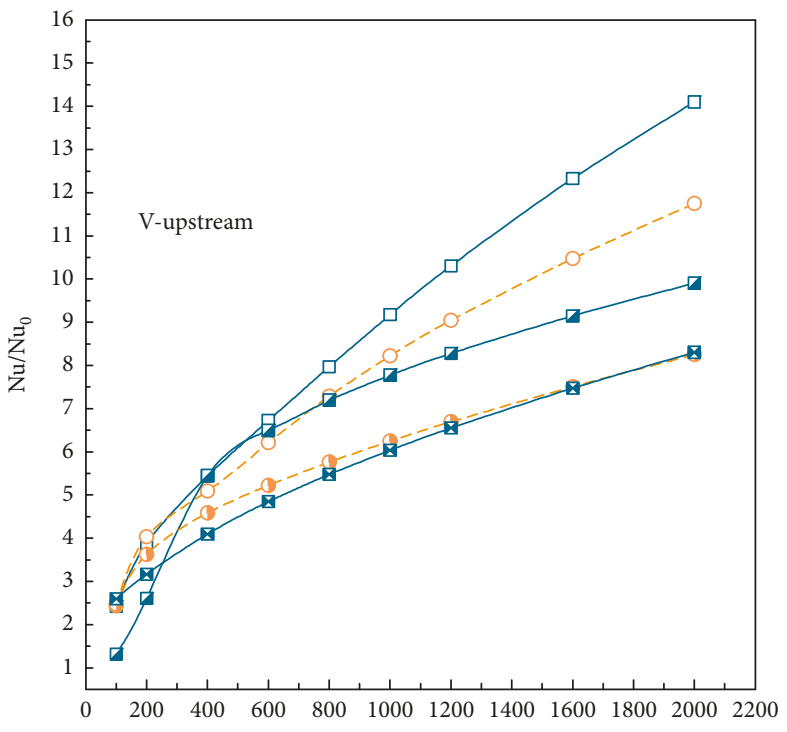

$\operatorname{Re}$

$$
\begin{array}{ll}
-\square-b_{20} g_{0} & -\square-b_{20} g_{15} \\
-\bigcirc-b_{20} g_{05} & -\square-b_{20} g_{20}
\end{array}
$$

(d)

Figure 12: Continued. 


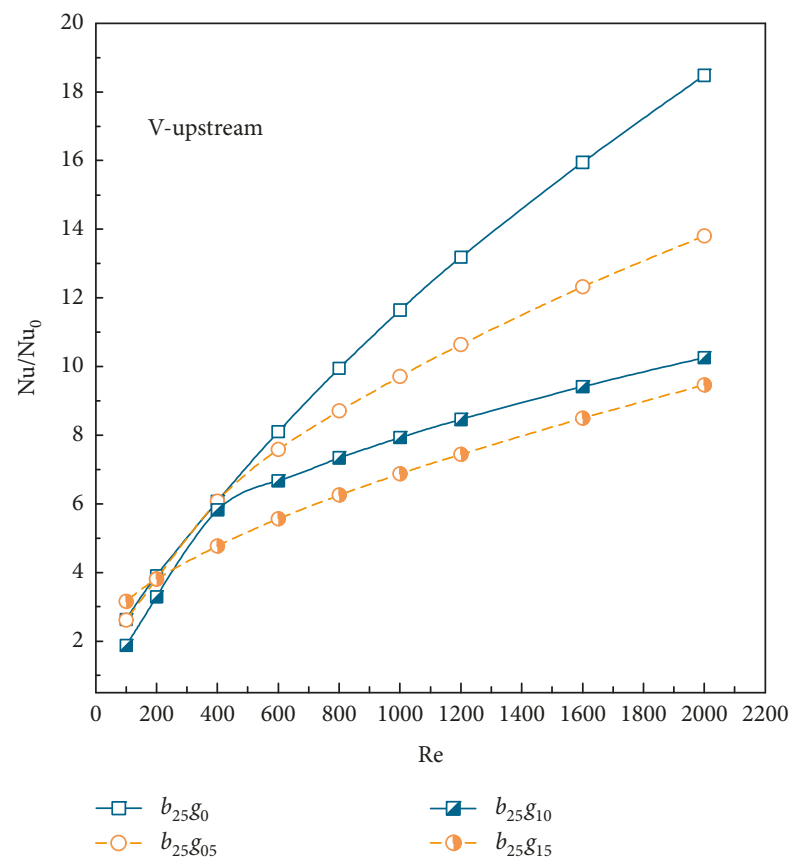

(e)

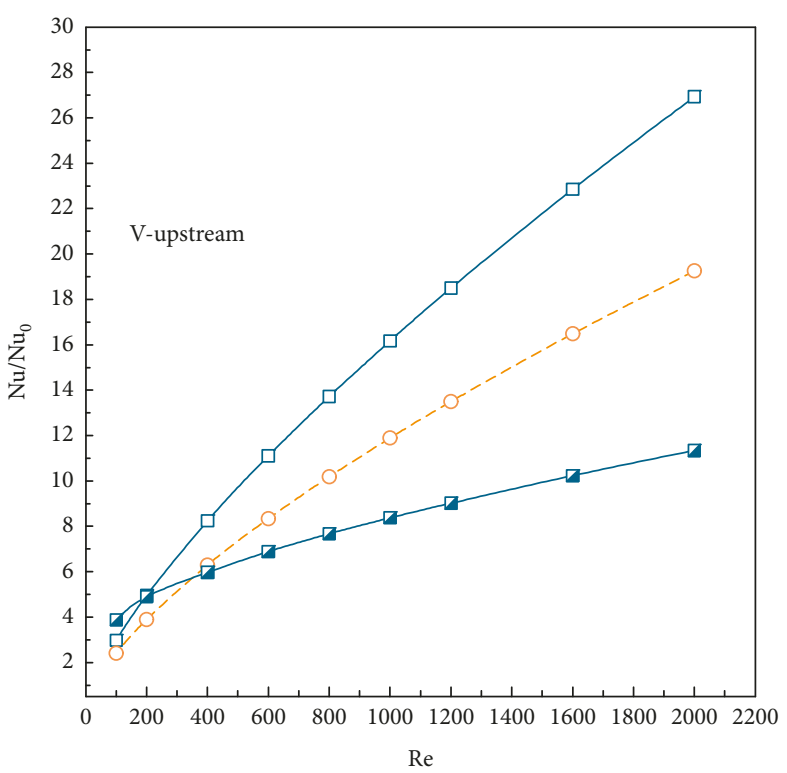

$-\square-b_{30} g_{0}$
$-\bigcirc-b_{30} g_{05}$
$\rightarrow-b_{30} g_{10}$

(f)

Figure 12: Relation of $\mathrm{Nu} / \mathrm{Nu}_{0}$ with the Reynolds number for (a) b05, (b) b10, (c) b15, (d) b20, (e) b25, and (f) b30 at V-upstream arrangement.
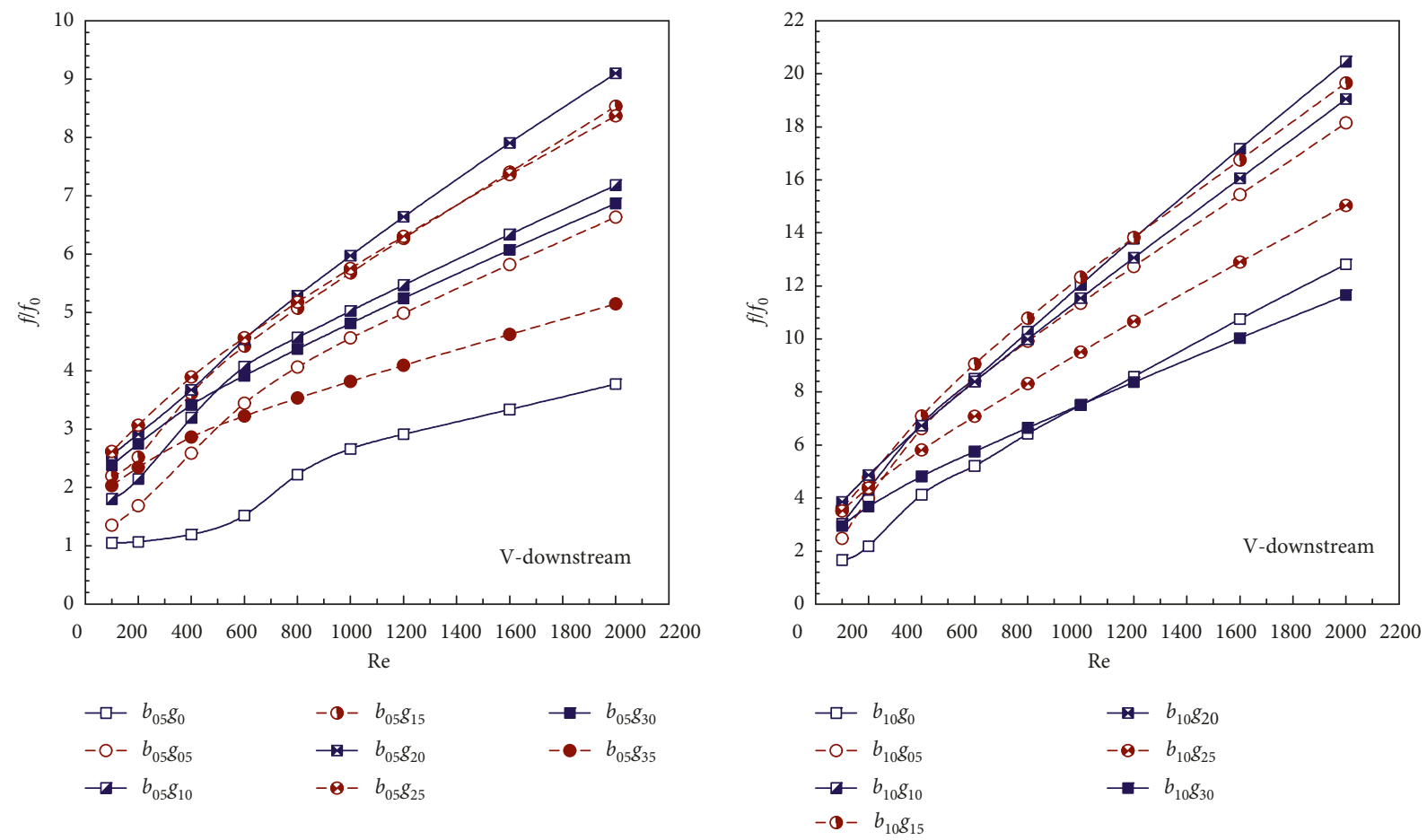

(a)

(b)

FIgure 13: Continued. 


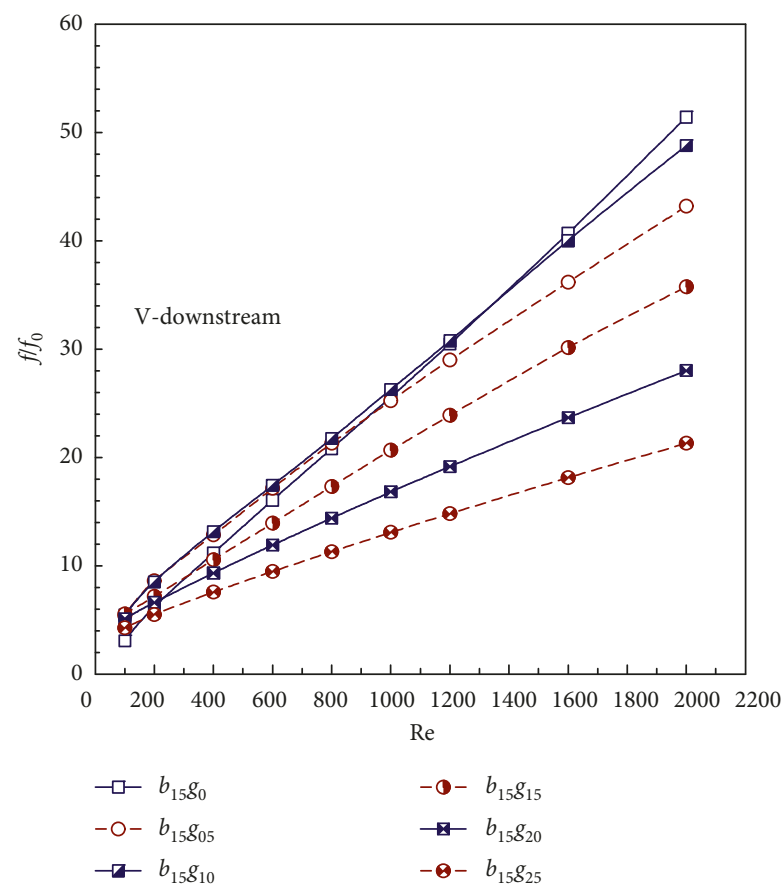

(c)

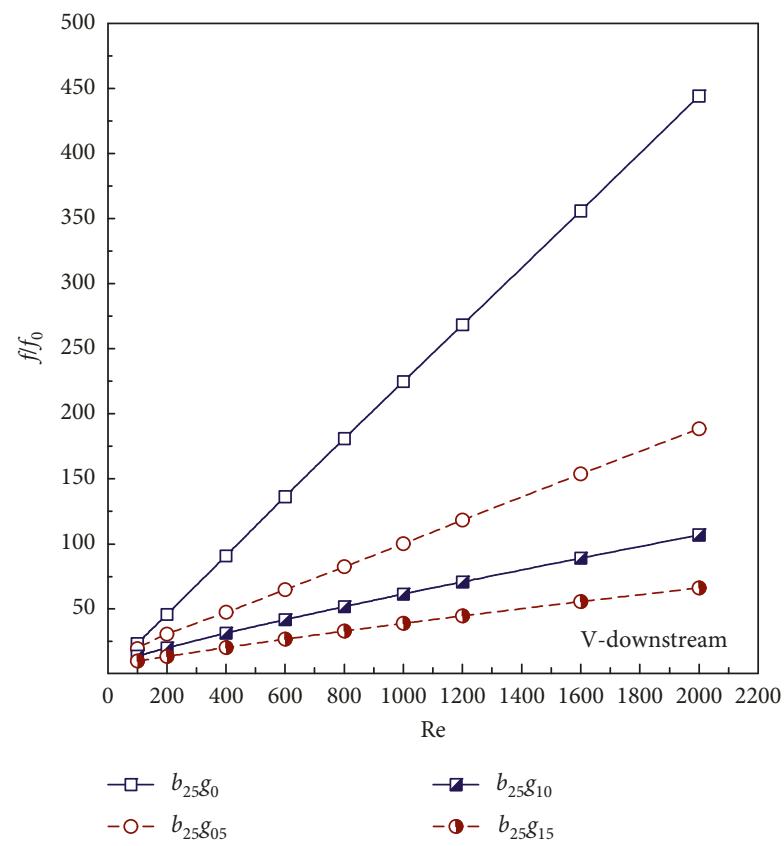

(e)

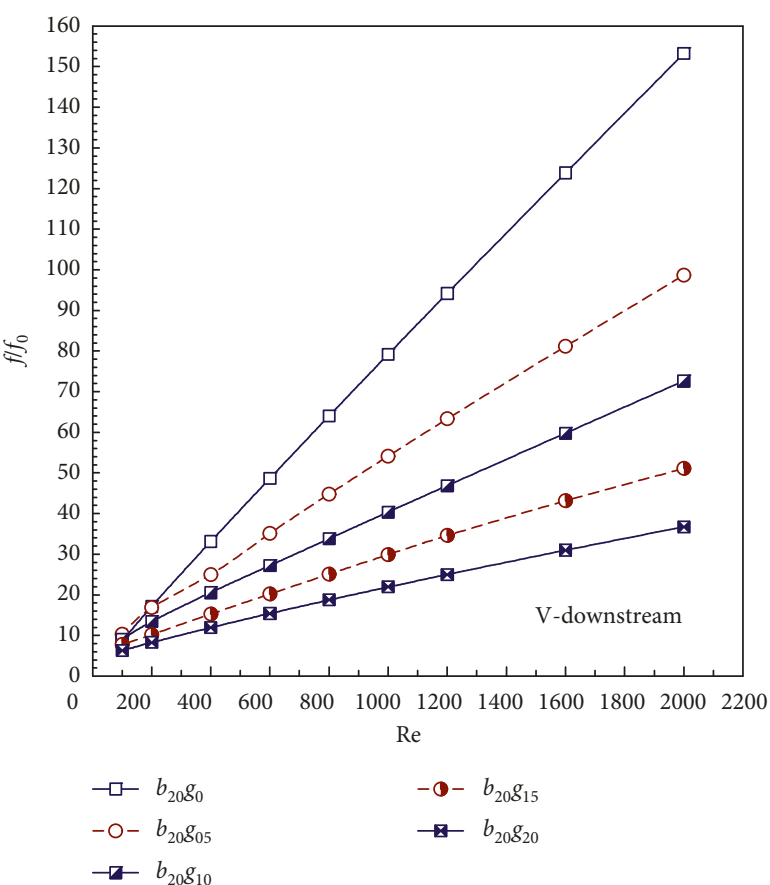

(d)

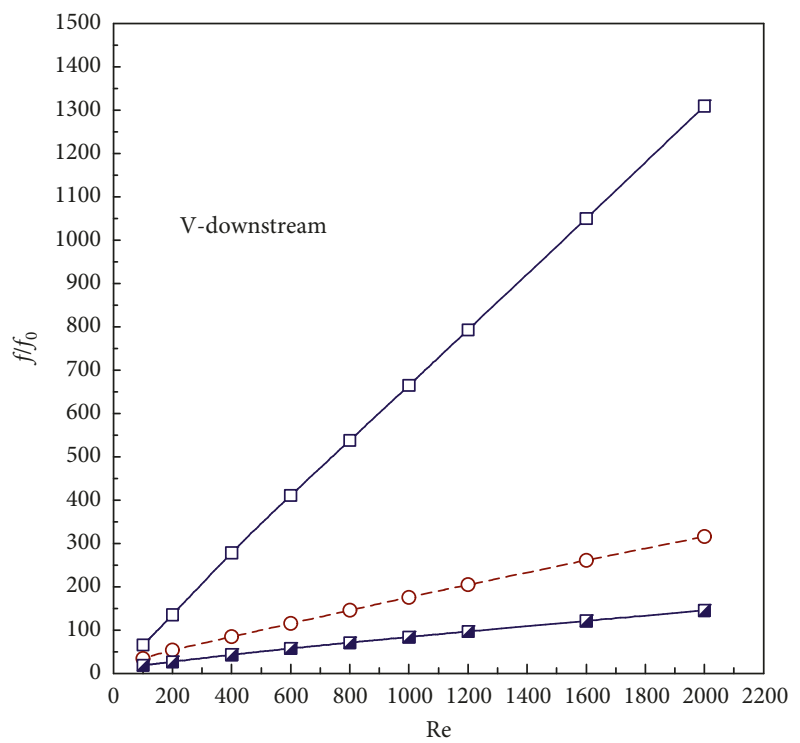

$-\square-b_{30} g_{0}$
$-\bigcirc-b_{30} g_{05}$
$-\square-b_{30} g_{10}$

(f)

Figure 13: Relation of $f / f_{0}$ with the Reynolds number for (a) b05, (b) b10, (c) b15, (d) b20, (e) b25, and (f) b30 at V-downstream arrangement.

blockage ratio. $f / f_{0}$ is around $1.00-10.14,1.60-25.71,4.05-91.11$, 5.96-237.45, 9.55-644.76, and 18.28-1928.77, respectively, for b05, b10, b15, b20, b25, and b30 at $\mathrm{Re}=100-2000$.

Because the installation of the $\mathrm{V}$-orifice in the heat exchanger channel increases both heat transfer rate and friction loss, the thermal enhancement factor is measured for the present investigation to check the advantage of the
$\mathrm{V}$-orifice in the heat exchanger channel. Figures 15(a)-15(f) show the relation of the TEF with the Reynolds number at various cases of V-downstream orifice at b05, b10, b15, b20, b25, and b30, respectively. Almost in all cases, the insertion of the $\mathrm{V}$-orifice in the heat exchanger channel can improve the thermal performance higher than the smooth channel $(\mathrm{TEF}>1)$. The TEF tends to increase when raising the 

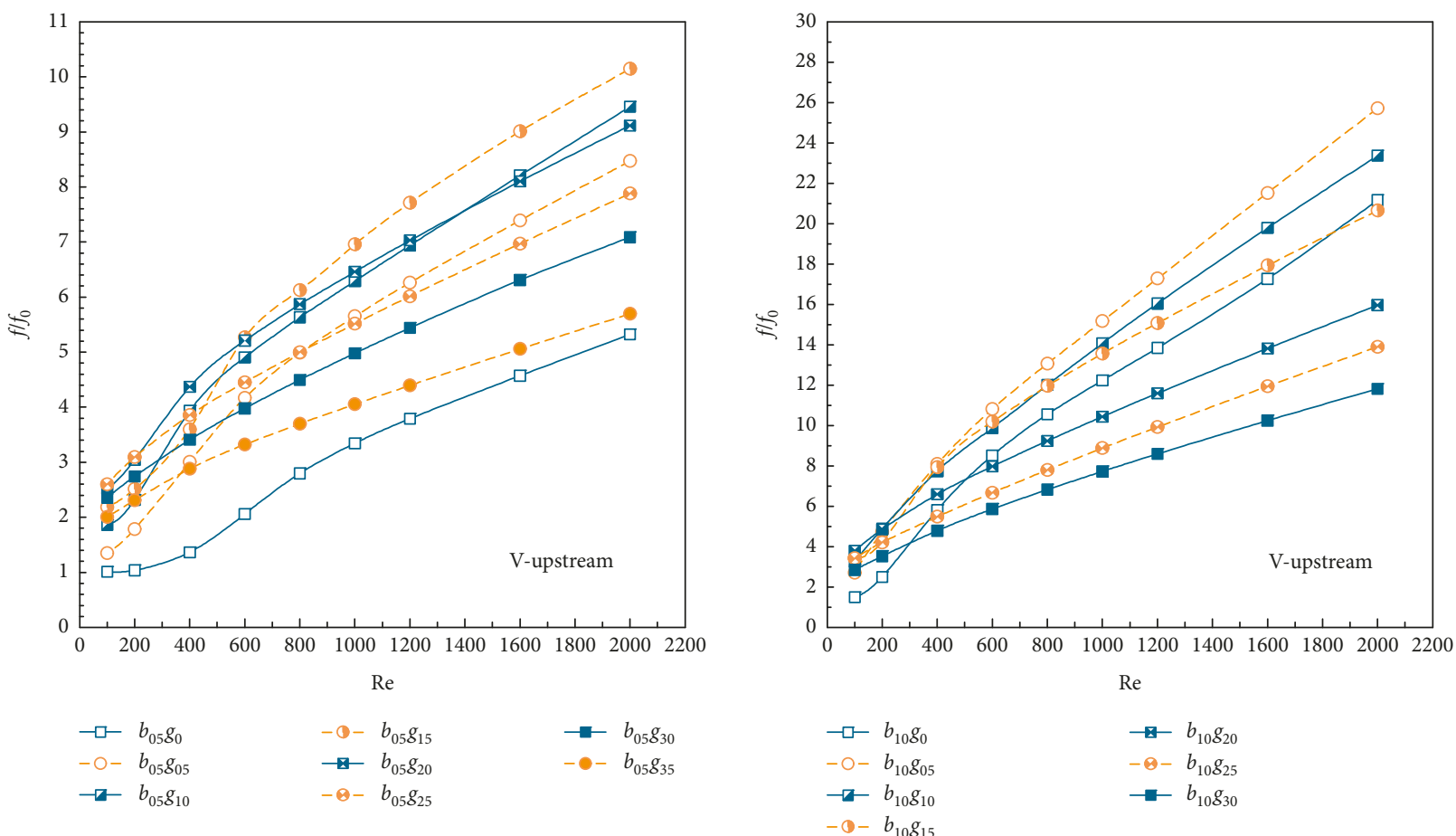

(a)
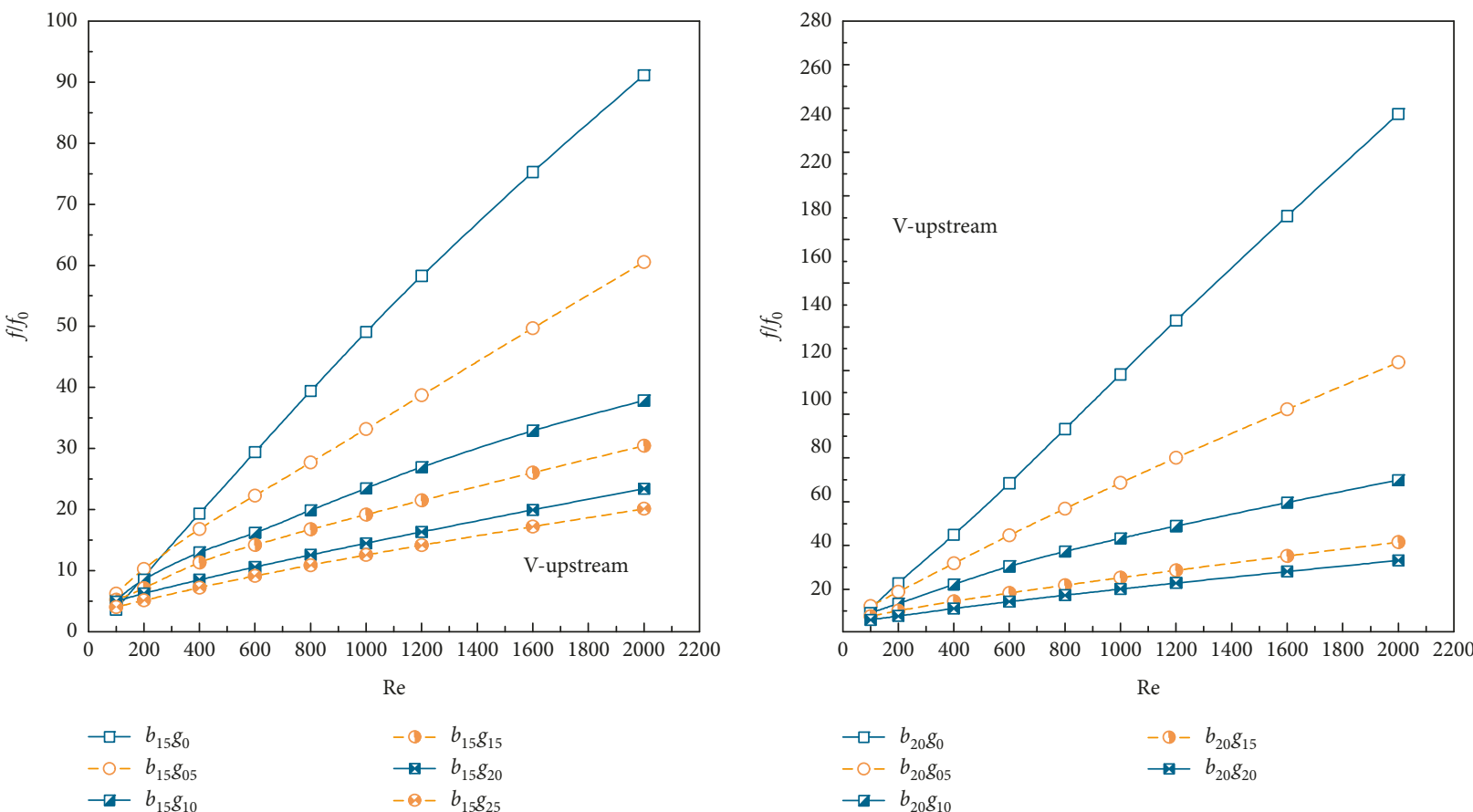

(c)

(d)

FIgURe 14: Continued. 


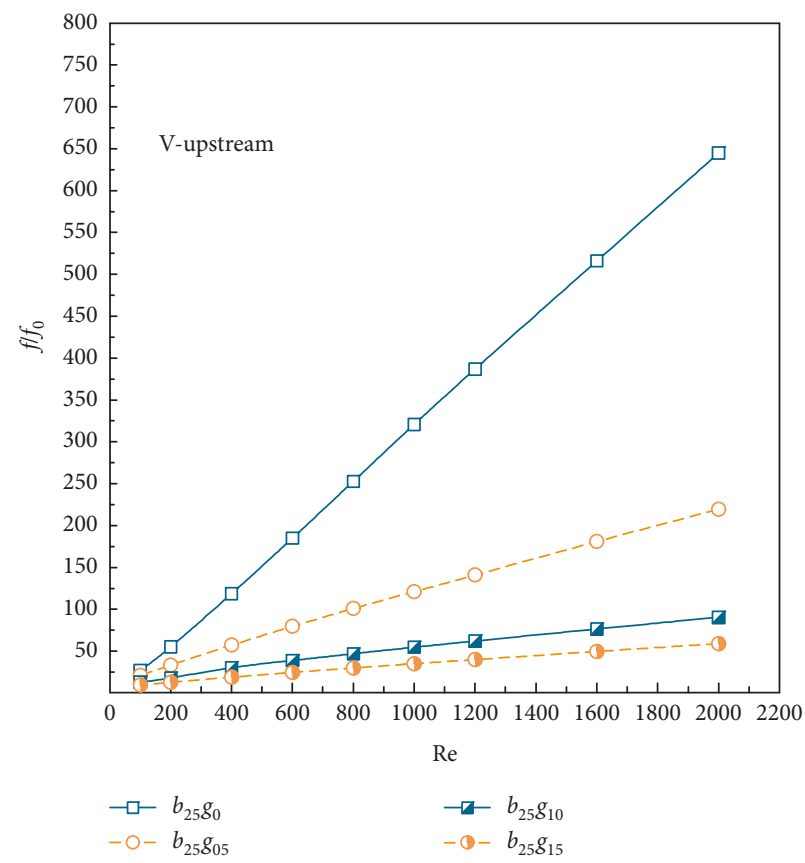

(e)

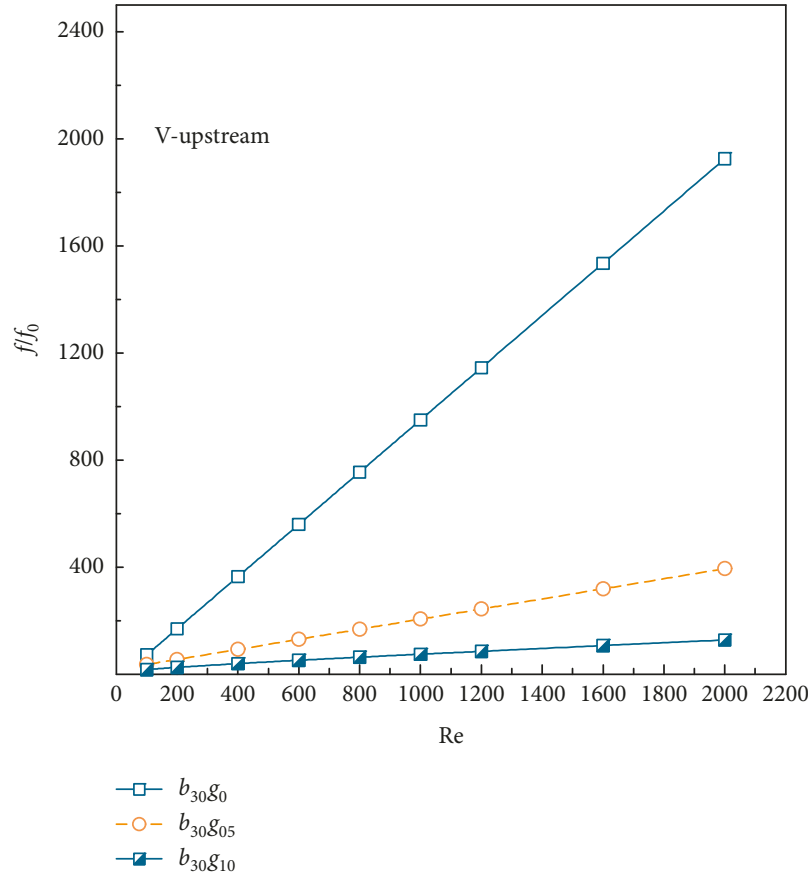

(f)

Figure 14: Relation of $f / f_{0}$ with the Reynolds number for (a) b05, (b) b10, (c) b15, (d) b20, (e) b25, and (f) b30 at V-upstream arrangement.
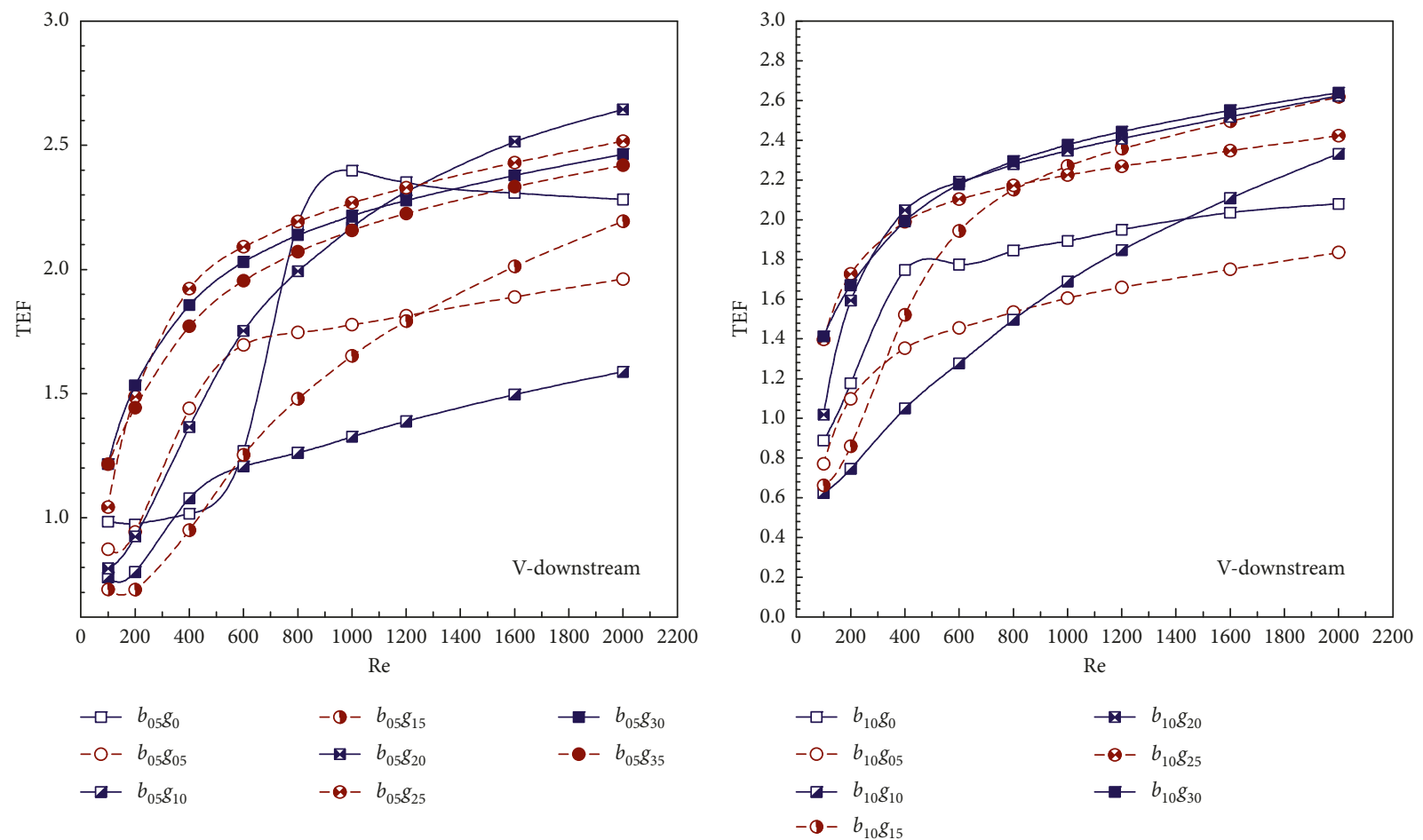

(a)

(b)

Figure 15: Continued. 

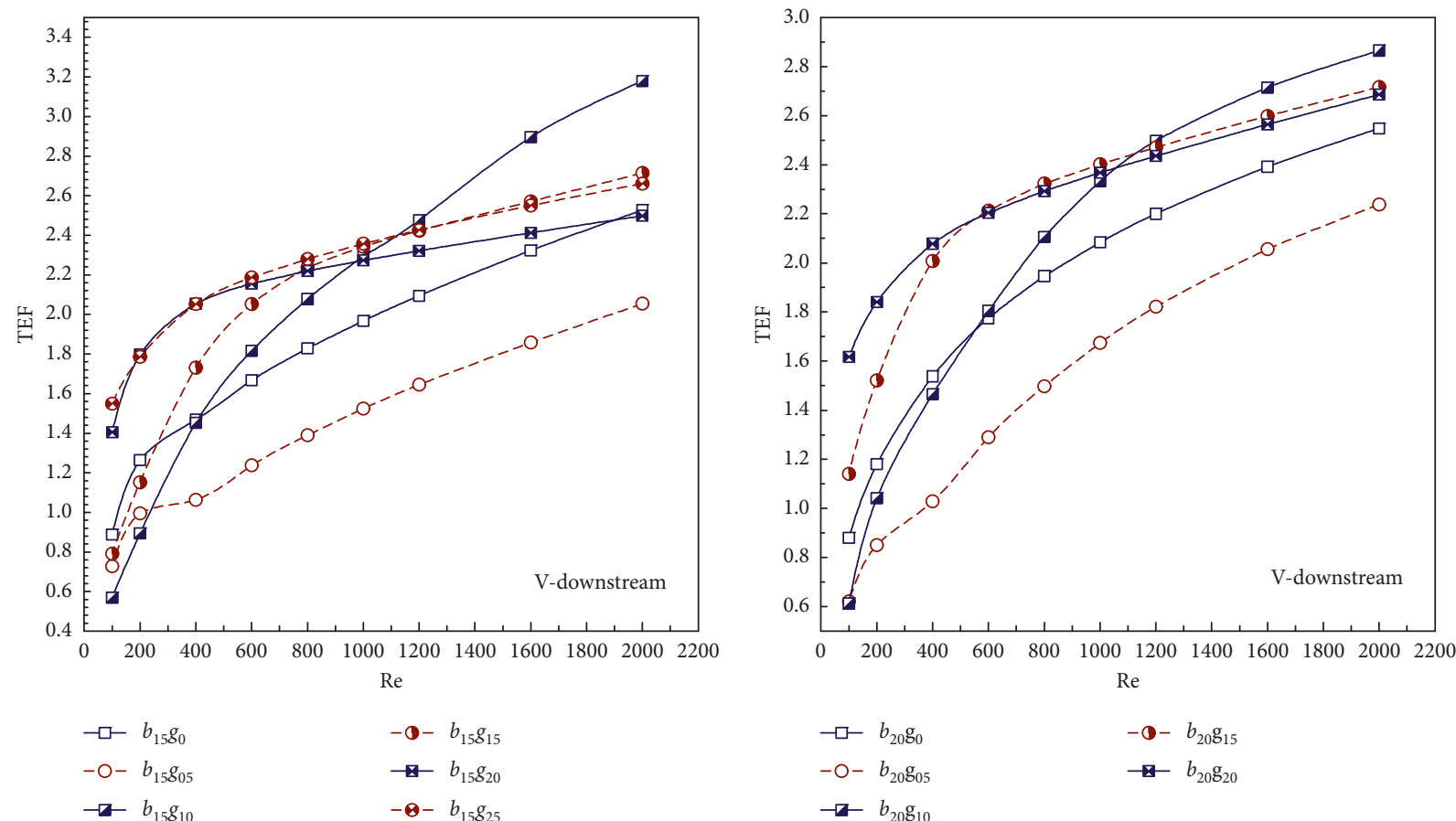

(d)
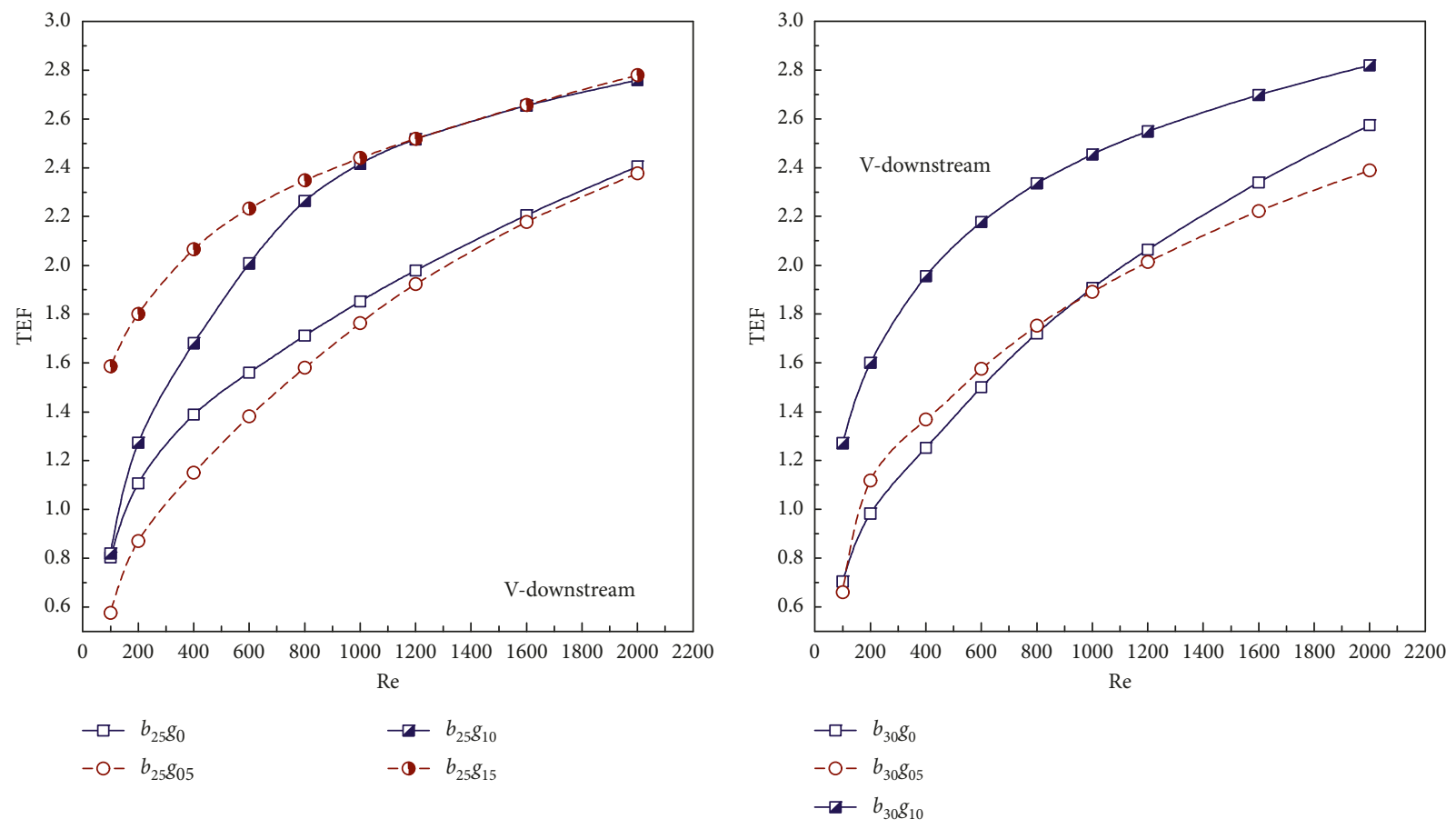

(e)

(f)

Figure 15: Relation of the TEF with the Reynolds number for (a) b05, (b) b10, (c) b15, (d) b20, (e) b25, and (f) b30 at V-downstream arrangement.

Reynolds number. The Reynolds number of 100 gives the lowest TEF, while the Reynolds number of 2000 provides the opposite result. Considering similar blockage ratio at $\mathrm{Re}=2000, \mathrm{~g} 20, \mathrm{~g} 30, \mathrm{~g} 10, \mathrm{~g} 10, \mathrm{~g} 15$, and g10 give the best TEF for b05, b10, b15, b20, b25, and b30, respectively, around $2.60,2.60,3.20,2.85,2.75$, and 2.80 .
The nearly pattern of the TEF is found in the case of $\mathrm{V}$-upstream arrangement as illustrated in Figure 16. At $\mathrm{Re}=2000$ and similar blockage ratio, g35, g05, g0, g20, g15, and g05 lead to the highest TEF at b05, b10, b15, b20, b25, and b30, respectively, around $2.60,3.00,2.85,2.55,2.45$, and 2.60 . 

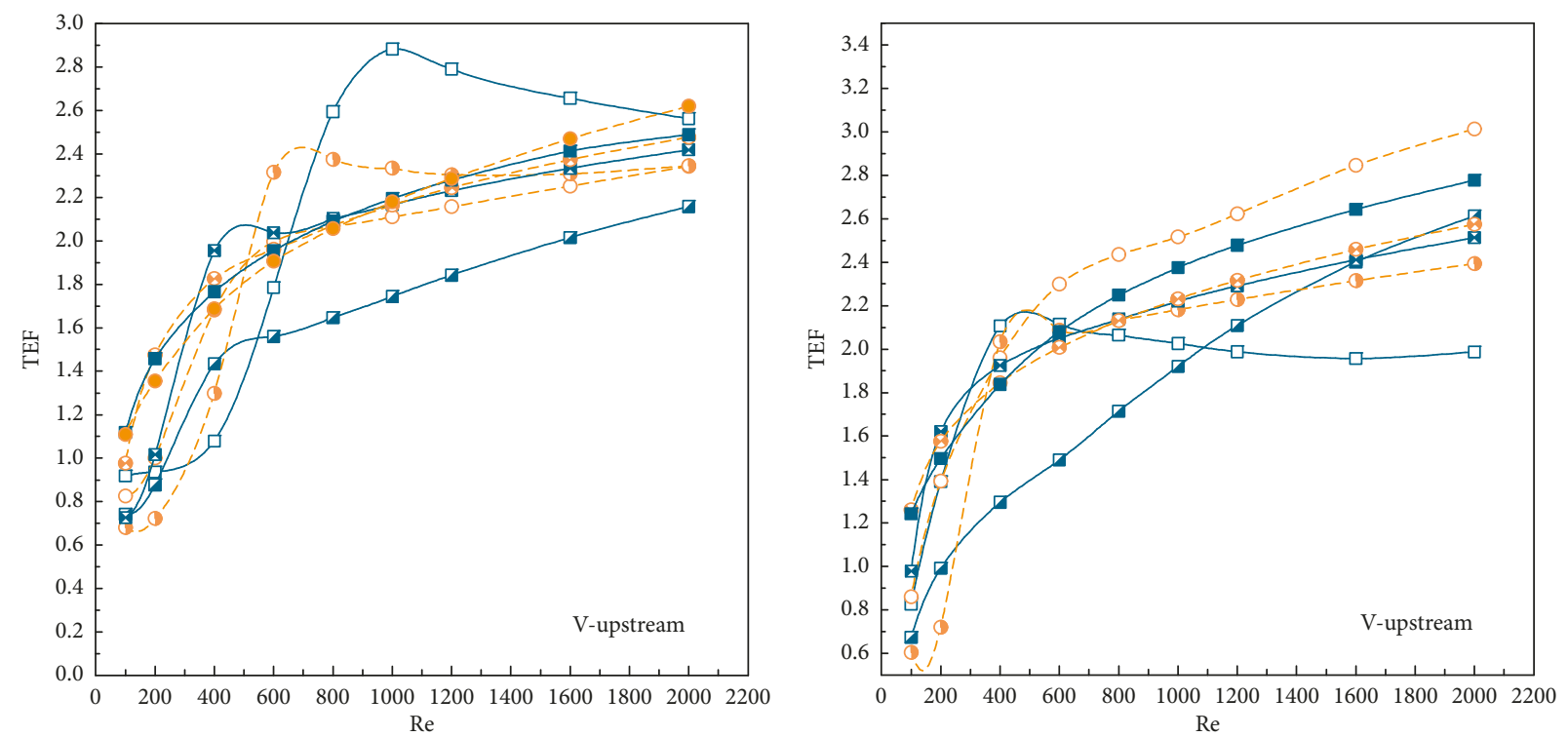

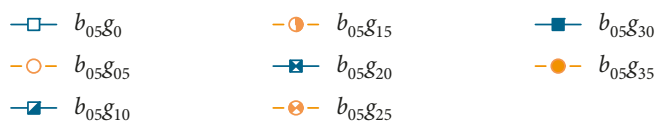

(a)

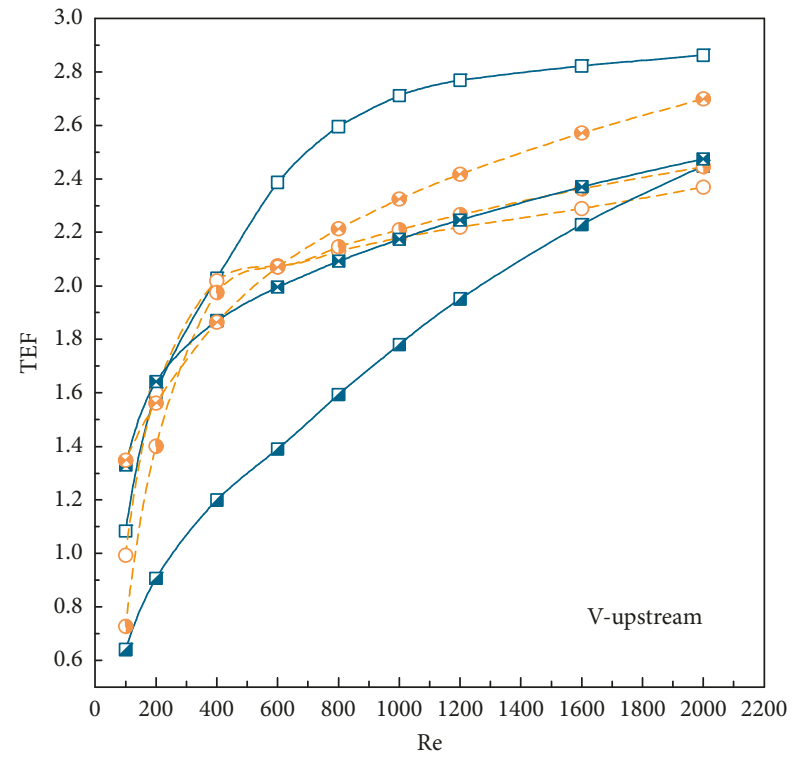

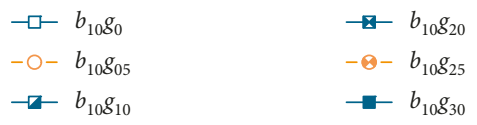

(b)

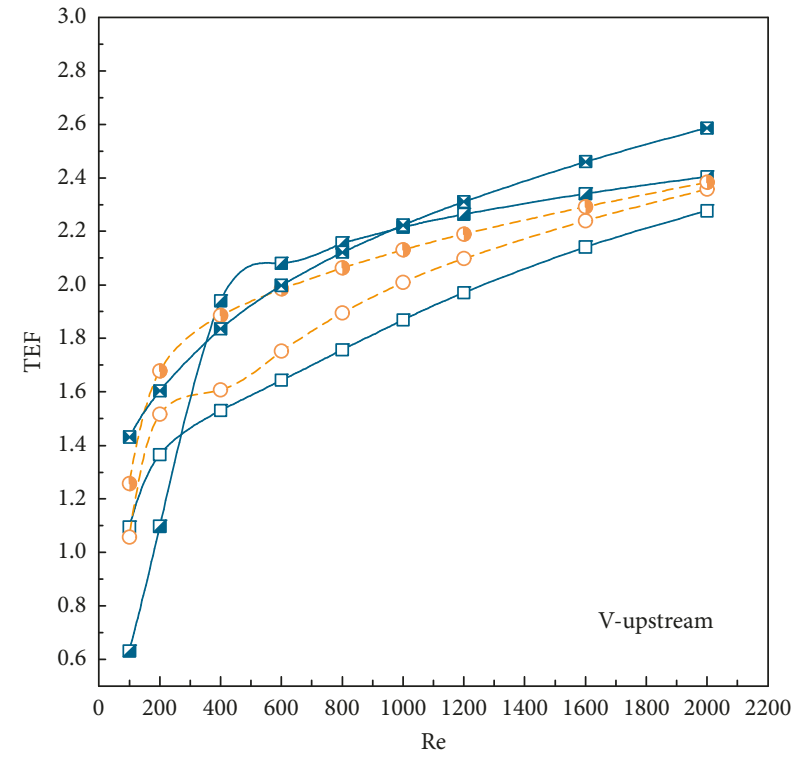

$$
\begin{array}{ll}
\neg-b_{20} g_{0} & -\square-b_{20} g_{15} \\
-\bigcirc-b_{20} g_{05} & \square-b_{20} g_{20}
\end{array}
$$$$
\rightarrow-b_{20} g_{10}
$$

(c)

(d)

Figure 16: Continued. 


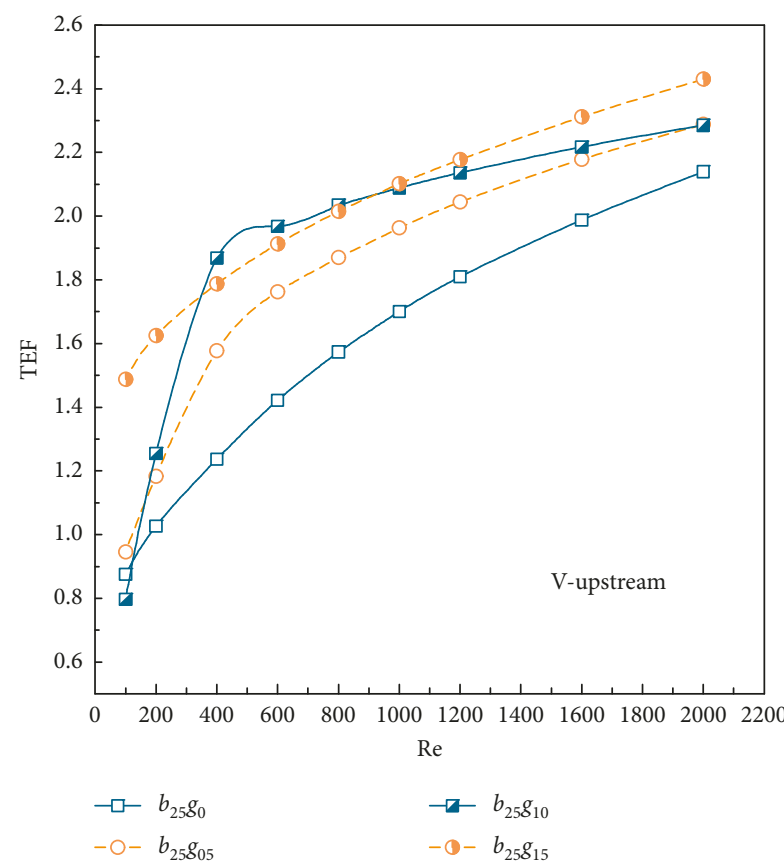

(e)

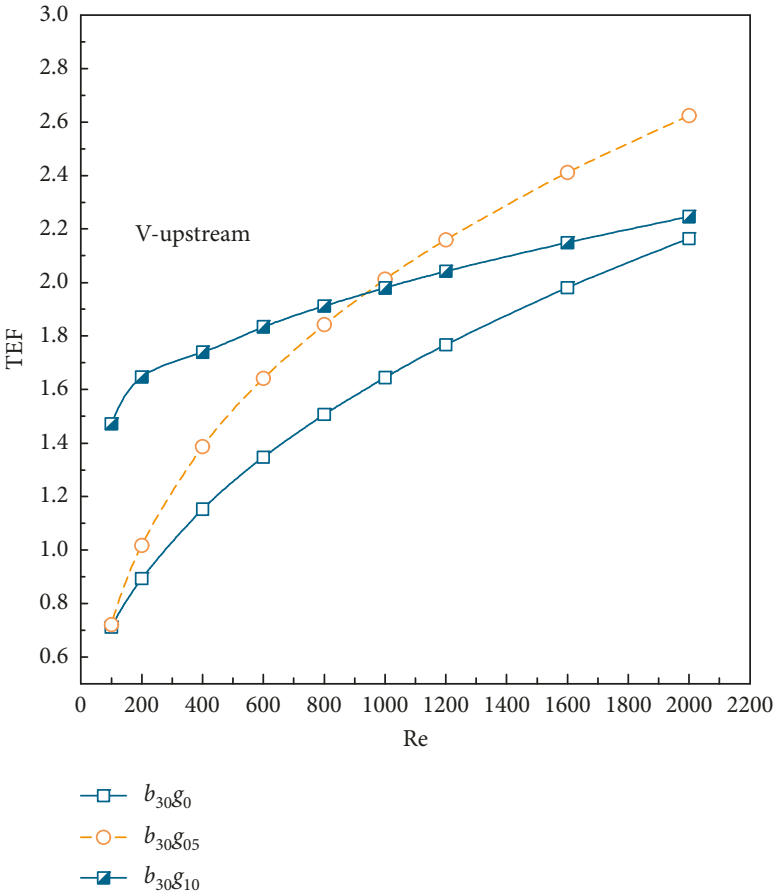

(f)

Figure 16: Relation of the TEF with the Reynolds number for (a) b05, (b) b10, (c) b15, (d) b20, (e) b25, and (f) b30 at V-upstream arrangement.

\section{Conclusion}

Convective heat transfer, flow visualization, and thermal performance assessment in the square channel heat exchanger installed with various parameters of the V-orifice are performed. The influences of the blockage ratio, gap spacing ratio and flow direction on heat transfer, and flow structure are considered for the laminar regime, $\mathrm{Re}=100-$ 2000. The numerical method is selected to solve the numerical problem. The major outcomes from the present investigation can be concluded as follows.

The $\mathrm{V}$-orifice can generate the vortex flow through the test section in all examples. The vortex flow is a key to enhance heat transfer rate and thermal performance. The vortex flow helps to improve the fluid mixing between core of the channel and near the channel walls. The vortex flow also disturbs the thermal boundary layer on the heat transfer surface.

The vortex strength increases when enhancing the blockage ratio. The gap spacing between the edges of the orifice and the channel walls can help to reduce the pressure loss in the test section and also augments the turbulent mixing.

The arrangement of the $\mathrm{V}$-orifice affects the variation of heat transfer regime. The $\mathrm{V}$-downstream arrangement provided the peak of heat transfer regime at the upper-lower parts of the channel, while the $\mathrm{V}$-upstream arrangement gives the highest heat transfer region at the left-right sidewalls.

The suggestion of the optimum gap spacing ratio is around 5-10\%, which generates the best thermal performance, while the vortex strength lightly decreases when compared with no gap $(g=0)$.

\section{Nomenclature}

BR: Flow blockage ratio $(=b / H)$

$b$ : Orifice height $(\mathrm{m})$

$D_{\mathrm{h}}$ : Hydraulic diameter of channel $\left(D_{\mathrm{h}}=H\right)$

$f$ : Friction factor

$g: \quad$ Gap spacing $(\mathrm{m})$

$h$ : Convective heat transfer coefficient $\left(\mathrm{W} \cdot \mathrm{m}^{-2} \cdot \mathrm{K}^{-1}\right)$

$k$ : Thermal conductivity $\left(\mathrm{W} \cdot \mathrm{m}^{-1} \cdot \mathrm{K}^{-1}\right)$

$\mathrm{Nu}$ : Nusselt number $\left(=h \cdot D_{\mathrm{h}} / k\right)$

$P: \quad$ Distance between ribs (m)

$p: \quad$ Static pressure $(\mathrm{Pa})$

Pr: Prandtl number $(\operatorname{Pr}=0.707)$

PR: Pitch or spacing ratio $(=P / H)$

Re: Reynolds number $(=\rho \bar{u} D / \mu)$

T: $\quad$ Temperature $(\mathrm{K})$

$u_{i}$ : Velocity in $x_{i}$-direction $\left(\mathrm{m} \cdot \mathrm{s}^{-1}\right)$

$\bar{u}$ : $\quad$ Mean velocity in channel $\left(\mathrm{m} \cdot \mathrm{s}^{-1}\right)$

Greek letters

$\mu$ : Dynamic viscosity $\left(\mathrm{kg} \cdot \mathrm{s}^{-1} \cdot \mathrm{m}^{-1}\right)$

$\Gamma: \quad$ Thermal diffusivity $\left(=k / \rho c_{\mathrm{p}}\right)$

$\alpha$ : Angle of attack, degree

TEF: Thermal enhancement factor $\left(=\left(\mathrm{Nu} / \mathrm{Nu}_{0}\right) /\left(f / f_{0}\right)^{1 / 3}\right)$

$\rho: \quad$ Density $\left(\mathrm{kg} \cdot \mathrm{m}^{-3}\right)$

\section{Subscripts}

in: Inlet

0: Smooth tube

pp: Pumping power. 


\section{Data Availability}

No data were used to support this study.

\section{Conflicts of Interest}

The authors declare that there are no conflicts of interest regarding the publication of this article.

\section{Acknowledgments}

This research was funded by the College of Industrial Technology, King Mongkut's University of Technology North Bangkok (Grant no. Res-CIT0230/2019). The authors would like to thank Associate Prof. Dr. Pongjet Promvonge, KMITL, for suggestions.

\section{References}

[1] J. Du, Y. Hong, S.-M. Huang, W.-B. Ye, and S. Wang, "Laminar thermal and fluid flow characteristics in tubes with sinusoidal ribs," International Journal of Heat and Mass Transfer, vol. 120, pp. 635-651, 2018.

[2] L. Chai, L. Wang, and X. Bai, "Thermohydraulic performance of microchannel heat sinks with triangular ribs on sidewalls-part 1: local fluid flow and heat transfer characteristics," International Journal of Heat and Mass Transfer, vol. 127, pp. 1124-1137, 2018.

[3] I. Singh and S. Singh, "CFD analysis of solar air heater duct having square wave profiled transverse ribs as roughness elements," Solar Energy, vol. 162, pp. 442-453, 2018.

[4] A. Kumar and A. Layek, "Nusselt number and friction factor correlation of solar air heater having twisted-rib roughness on absorber plate," Renewable Energy, vol. 130, pp. 687-699, 2019.

[5] A. Kumar and A. Layek, "Thermo-hydraulic performance of solar air heater having twisted rib over the absorber plate," International Journal of Thermal Sciences, vol. 133, pp. 181195, 2018.

[6] R. Kumar, R. Chauhan, M. Sethi, and A. Kumar, "Experimental study and correlation development for Nusselt number and friction factor for discretized broken V-pattern baffle solar air channel," Experimental Thermal and Fluid Science, vol. 81, pp. 56-75, 2017.

[7] W. Jedsadaratanachai, N. Jayranaiwachira, and P. Promvonge, "3D numerical study on flow structure and heat transfer in a circular tube with V-baffles," Chinese Journal of Chemical Engineering, vol. 23, no. 2, pp. 342-349, 2015.

[8] W. Jedsadaratanachai and A. Boonloi, "Effects of blockage ratio and pitch ratio on thermal performance in a square channel with $30^{\circ}$ double V-baffles," Case Studies in Thermal Engineering, vol. 4, pp. 118-128, 2014.

[9] S. Caliskan and S. Baskaya, "Velocity field and turbulence effects on heat transfer characteristics from surfaces with V-shaped ribs," International Journal of Heat and Mass Transfer, vol. 55, no. 21-22, pp. 6260-6277, 2012.

[10] D. Jin, J. Zuo, S. Quan, S. Xu, and H. Gao, “Thermohydraulic performance of solar air heater with staggered multiple V-shaped ribs on the absorber plate," Energy, vol. 127, pp. 68-77, 2017.

[11] N. S. Deo, S. Chander, and J. S. Saini, "Performance analysis of solar air heater duct roughened with multigap V-down ribs combined with staggered ribs," Renewable Energy, vol. 91, pp. 484-500, 2016.

[12] P. Promthaisong, P. Eiamsa-Ard, W. Jedsadaratanachai, and S. Eiamsa-Ard, "Turbulent heat transfer and pressure loss in a square channel with discrete broken V-rib turbulators," Journal of Hydrodynamics, vol. 28, no. 2, pp. 275-283, 2016.

[13] X. Fang, Z. Yang, B.-C. Wang, M. F. Tachie, and D. J. Bergstrom, "Highly-disturbed turbulent flow in a square channel with V-shaped ribs on one wall," International Journal of Heat and Fluid Flow, vol. 56, pp. 182-197, 2015.

[14] R. Maithani and J. S. Saini, "Heat transfer and friction factor correlations for a solar air heater duct roughened artificially with V-ribs with symmetrical gaps," Experimental Thermal and Fluid Science, vol. 70, pp. 220-227, 2016.

[15] D. Jin, M. Zhang, P. Wang, and S. Xu, "Numerical investigation of heat transfer and fluid flow in a solar air heater duct with multi V-shaped ribs on the absorber plate," Energy, vol. 89, pp. 178-190, 2015.

[16] W. Jedsadaratanachai and A. Boonloi, "Numerical study on turbulent forced convection and heat transfer characteristic in a circular tube with V-orifice," Modelling and Simulation in Engineering, vol. 2017, Article ID 3816739, 20 pages, 2017.

[17] Y. A. Çengel and A. J. Ghajar, "Heat and mass transfer: fundamentals \& applications," in SI Units, McGraw-Hill Education, New York, NY, USA, 5th edition, 2015, ISBN 978-981-4595-27-8. 


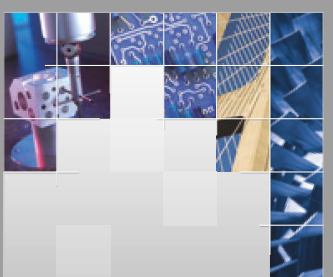

\section{Enfincering}
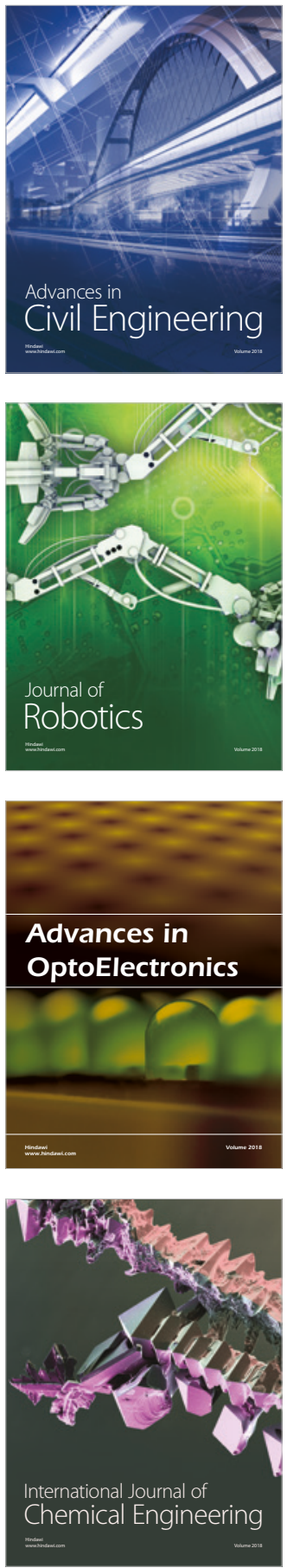

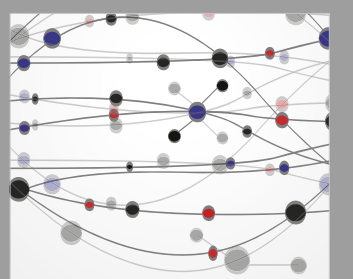

\section{Rotating \\ Machinery}

The Scientific World Journal

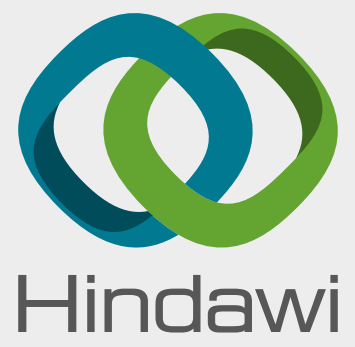

Submit your manuscripts at

www.hindawi.com
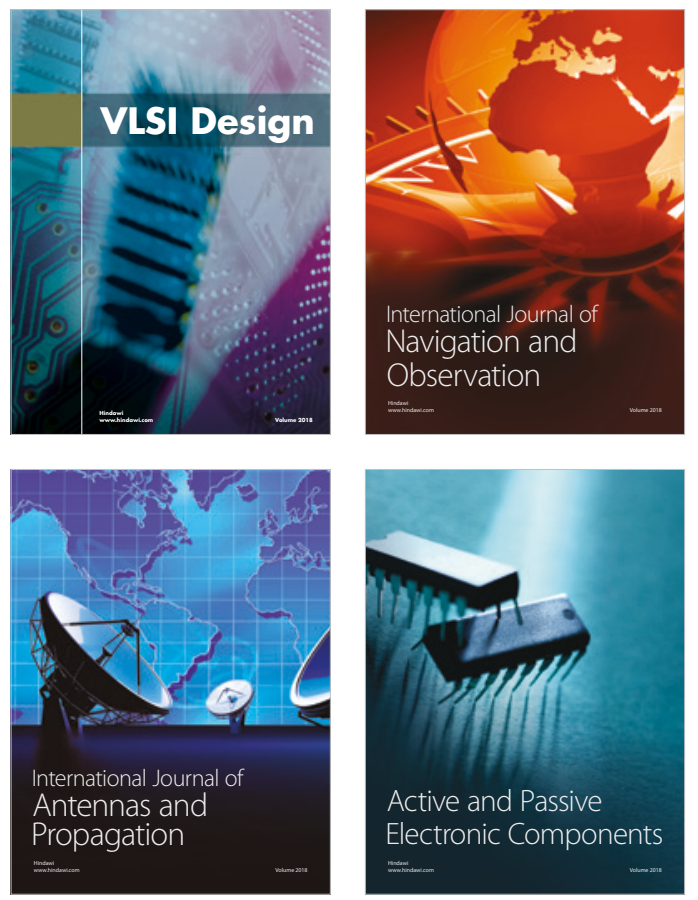
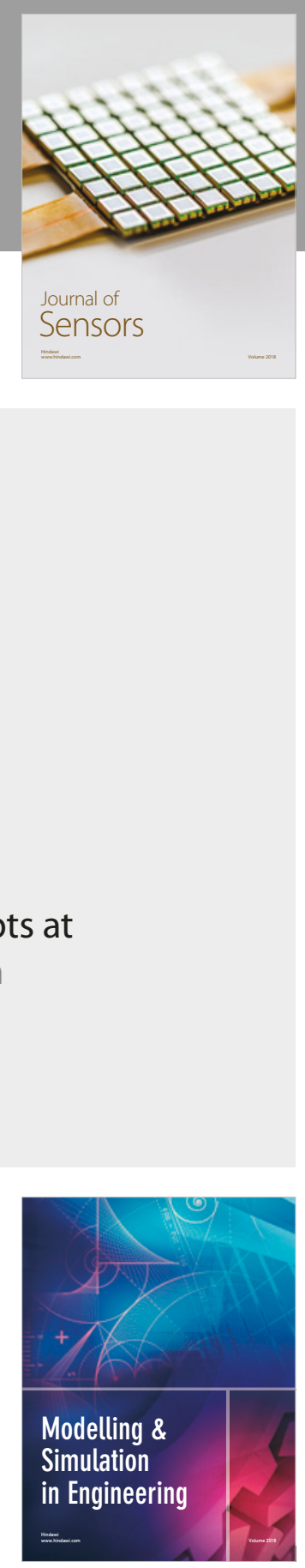

\section{Advances \\ Multimedia}
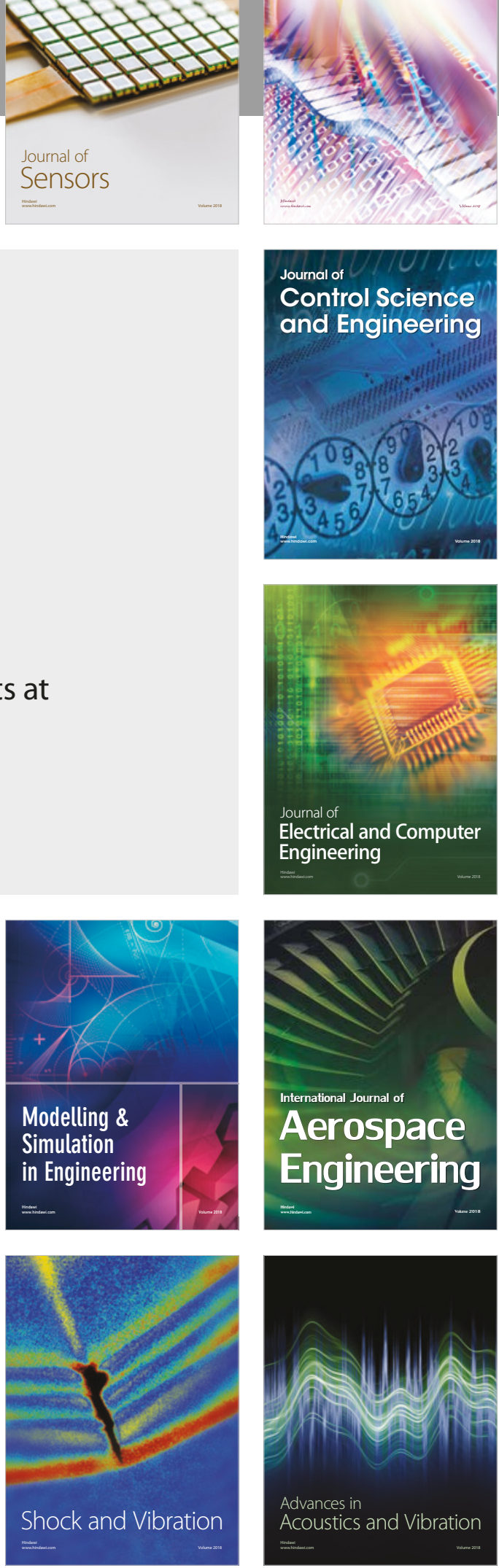